\title{
Contract Design of Direct-Load Control Programs and Their Optimal Management by Genetic Algorithm
}

\author{
Juan M. Lujano-Rojas ${ }^{\mathrm{a}, \mathrm{b}, 1}$, Ghassan Zubi ${ }^{\mathrm{c}}$, Rodolfo Dufo-López ${ }^{\mathrm{d}}$, José L. Bernal-

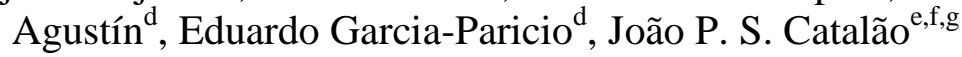 \\ ${ }^{a}$ Department for Management of Science and Technology Development, Ton Duc Thang University, Ho Chi Minh City, Vietnam. \\ ${ }^{b}$ Faculty of Electrical \& Electronics Engineering, Ton Duc Thang University, Ho Chi Minh City, Vietnam. \\ ${ }^{c}$ Triangle Research and Development Center, Israel. \\ ${ }^{d}$ Department of Electrical Engineering, Universidad de Zaragoza, Calle María de Luna 3, 50018 Zaragoza, Spain. \\ ${ }^{e}$ C-MAST, University of Beira Interior, R. Fonte do Lameiro, 6201-001 Covilhã, Portugal \\ ${ }^{f}$ INESC-ID, Instituto Superior Técnico, University of Lisbon, Av. Rovisco Pais, 1, 1049-001 Lisbon, Portugal \\ ${ }^{g}$ INESC TEC and Faculty of Engineering of the University of Porto, R. Dr. Roberto Frias, 4200-465 Porto, Portugal
}

\begin{abstract}
A computational model for designing direct-load control (DLC) demand response (DR) contracts is presented in this paper. The critical and controllable loads are identified in each node of the distribution system (DS). Critical loads have to be supplied as demanded by users, while the controllable loads can be connected during a determined time interval. The time interval at which each controllable load can be supplied is determined by means of a contract or compromise established between the utility operator and the corresponding consumers of each node of the DS. This approach allows us to reduce the negative impact of the DLC program on consumers' lifestyles. Using daily forecasting of wind speed and power, solar radiation and temperature, the optimal allocation of DR resources is determined by solving an optimization problem through a genetic algorithm where the energy content of conventional power generation and battery discharging energy are minimized. The proposed approach was illustrated by analyzing a system located in the Virgin Islands. Capabilities and characteristics of the proposed method in daily and annual terms are fully discussed, as well as the influence of forecasting errors.
\end{abstract}

Keywords: demand response, direct-load control, microgrid, genetic algorithm

\section{List of symbols}

\begin{tabular}{|cl|}
\hline$h$ & Index for the hour of the day $(h=1, \ldots, H=24)(\mathrm{h})$. \\
$j$ & Index for the type of demand response contract $(j=1, \ldots, J)$. \\
$k$ & Index for iterations of power flow analysis $(k=1, \ldots, K)$. \\
$l, u$ & Indexes for a general purpose counter. \\
$m_{(j)}$ & Index for the rows of matrix $P_{\left(m_{(j)}, h, j\right)}$ when contract $j$ is considered \\
$n$ & $\left(m_{(j)}=1, \ldots, M_{(j)}\right)$. \\
$r$ & Index for the nodes of distribution system $(n=1, \ldots, N)$. \\
$y$ & Index for each individual of genetic algorithm $(r=1, \ldots, R)$. \\
$\vec{a}_{(r)}$ & Index for each scenario of wind generation $(y=1, \ldots, Y)$. \\
$a_{(r, j)}$ & Element of individual $r$ and contract $j$. \\
$A$ & Genetic-algorithm population. \\
$B C B V$ & Branch-current to bus-voltage matrix. \\
$B I B C$ & Bus-injection to branch-current matrix. \\
$c_{1}^{O}$ & Parameter of objective function calculation. \\
$C_{(n)}$ & Type of contract of the consumer connected to node $n$. \\
$E_{r}^{B}$ & Rated capacity of battery storage system $(\mathrm{kWh})$. \\
$E_{S}$ & Total energy content on controllable power sources $(\mathrm{kWh})$. \\
$E_{S(y)}$ & Total energy content on controllable power sources for scenario $y$ \\
\hline
\end{tabular}

\footnotetext{
${ }^{1}$ Corresponding author at: lujano.juan@tdt.edu.vn
} 


\begin{tabular}{|c|c|}
\hline & $(\mathrm{kWh})$. \\
\hline$E N S_{(h)}$ & Energy not supplied at time $h(\mathrm{kWh})$. \\
\hline$E N S_{(h, y)}$ & Energy not supplied at time $h$ and scenario $y(\mathrm{kWh})$. \\
\hline$F_{(h)}^{D}$ & Fuel consumption of diesel generator at time $h$ (liters). \\
\hline$F_{(h, y)}^{D}$ & Fuel consumption of diesel generator at time $h$ and scenario $y$ (liters). \\
\hline$L H V_{F}$ & Low heating value of diesel fuel $(\mathrm{MJ} / \mathrm{kg})$. \\
\hline$I_{(h, k, n)}^{G}$ & Current of branch $n$ during iteration $k$ at time $h$. \\
\hline$I_{(h, k, n, y)}^{G}$ & Current of branch $n$ during iteration $k$ at time $h$ and scenario $y$. \\
\hline$I_{(h, n)}^{G, \max }$ & Ampacity of branch $n$ at time $h(\mathrm{~A})$. \\
\hline$I_{(h, n, y)}^{G, \max }$ & Ampacity of branch $n$ at time $h$ and scenario $y$ (A). \\
\hline$\vec{I}_{(h, k)}^{G}$ & Vector of branch currents at iteration $k$ and time $h(\mathrm{~A})$. \\
\hline$\vec{I}_{(h, k, y)}^{G}$ & Vector of branch currents at iteration $k$, time $h$ and scenario $y(\mathrm{~A})$. \\
\hline Obj & Value of objective function ( $\mathrm{kWh})$. \\
\hline$P_{r}^{D, \min }$ & Minimum power of diesel generator $(\mathrm{kW})$. \\
\hline$P_{r}^{D, \max }$ & Maximum power of diesel generator $(\mathrm{kW})$. \\
\hline$P_{(h)}^{D}$ & Power production of diesel generator $(\mathrm{kW})$. \\
\hline$P_{(h, y)}^{D}$ & Power production of diesel generator at time $h$ and scenario $y(\mathrm{~kW})$. \\
\hline$P_{r}^{W}$ & Rated power of wind farm $(\mathrm{kW})$. \\
\hline$P_{(h)}^{W}$ & Wind power at time $h(\mathrm{~kW})$. \\
\hline$P_{(h, y)}^{W}$ & Wind power at time $h$ and scenario $y(\mathrm{~kW})$. \\
\hline$P_{r}^{I}$ & Rated power of converter $(\mathrm{kW})$. \\
\hline$P_{(h)}^{I}$ & Power flow through the converter $(\mathrm{kW})$. \\
\hline$P_{(h, y)}^{I}$ & Power flow through the converter at time $h$ and scenario $y(\mathrm{~kW})$. \\
\hline$P_{r}^{B}$ & Rated power of battery cell stack $(\mathrm{kW})$. \\
\hline$P_{(h)}^{B}$ & Battery power at time $h(\mathrm{~kW})$ \\
\hline$P_{(h, y)}^{B}$ & Battery power at time $h$ and scenario $y(\mathrm{~kW})$. \\
\hline$P_{(h, n)}^{F}$ & Active power flow of distribution system at time $h$ and branch $n(\mathrm{~kW})$. \\
\hline$P_{(h, n, y)}^{F}$ & $\begin{array}{l}\text { Active power flow of distribution system at time } h \text {, branch } n \text { and } \\
\text { scenario } y(\mathrm{~kW}) \text {. }\end{array}$ \\
\hline$P_{(h, n)}^{G, R}$ & Heat loss by radiation of branch $n$ at time $h(\mathrm{~W} / \mathrm{m})$. \\
\hline$P_{(h, n)}^{G, C}$ & Heat loss by convection of branch $n$ at time $h(\mathrm{~W} / \mathrm{m})$. \\
\hline$P_{(h, n)}^{G, S}$ & Heat gained by solar radiation of branch $n$ at time $h(\mathrm{~W} / \mathrm{m})$. \\
\hline$P_{\left(m_{(j)}, h, j\right)}^{L}$ & Matrix of possible load profiles for loads enrolled to contract $j$. \\
\hline$P_{(h, n)}^{S}$ & Matrix of critical load profile for node $n$ at time $h(\mathrm{~kW})$. \\
\hline$P_{(h, n)}^{P}$ & Matrix of total load profile for node $n$ at time $h(\mathrm{~kW})$. \\
\hline$P_{(h)}^{N L}$ & Net load at time $h(\mathrm{~kW})$. \\
\hline$\Delta U_{G}$ & Error of power flow analysis. \\
\hline$\Delta P_{(n)}^{L}$ & Power required by controllable loads enrolled to contract $j(\mathrm{~kW})$. \\
\hline$R_{(n)}$ & Resistance of branch $n(\Omega)$. \\
\hline$S O C_{\min }^{B}$ & Minimum value of state of charge. \\
\hline$S O C_{\max }^{B}$ & Maximum value of state of charge. \\
\hline$S O C_{(h)}^{B}$ & Battery state of charge at time $h$. \\
\hline
\end{tabular}




\begin{tabular}{|cl|}
\hline$S O C_{(h, y)}^{B}$ & Battery state of charge at time $h$ and scenario $y$. \\
$\Delta S O C_{(h)}^{B}$ & Change on state of charge during discharge at time $h$. \\
$\Delta S O C_{(h, y)}^{B}$ & Change on state of charge during discharge at time $h$ and scenario $y$. \\
$t_{(j)}^{\min }$ & Earliest operation time of controllable loads for contract $j(\mathrm{~h})$. \\
$t_{(j)}^{\max }$ & Latest operation time of controllable loads for contract $j(\mathrm{~h})$. \\
$t_{(j)}$ & Starting operation time of controllable loads for contract $j(\mathrm{~h})$. \\
$\Delta t_{(j)}$ & Time required by controllable loads enrolled to contract $j$ (h). \\
$T_{(h, n)}^{I}$ & Value of weighting matrix for ampacity violation. \\
$T_{(h, n, y)}^{I}$ & Weighting matrix for ampacity violation at time $h$, branch $n$, scenario $y$. \\
$T_{(h, n)}^{U}$ & Value of weighting matrix for distribution-system voltage violation. \\
$T_{(h, n, y)}^{U}$ & Weighting matrix for voltage violation at time $h$ and scenario $y$. \\
$T_{(h)}^{E N S}$ & Value of weighting matrix for energy-not-supplied violation. \\
$T_{(h, y)}^{E N S}$ & Value of weighting matrix for energy-not-supplied violation at time $h$ \\
$U_{(h)}^{B}$ & and scenario $y$. \\
$U_{(h, y)}^{B}$ & Battery voltage at time $h(\mathrm{~V})$. \\
$U_{\min }^{B}$ & Minimum voltage of the battery (V). \\
$U_{\max }^{B}$ & Maximum voltage of the battery (V). \\
$U_{r}^{G, m i n}$ & Minimum operating voltage of distribution system. \\
$U_{(h, k, n)}^{G}$ & Voltage of node $n$ during iteration $k$ at time $h$. \\
$U_{(h, k, n, y)}^{G}$ & Voltage of node $n$ during iteration $k$ at time $h$ and scenario $y$. \\
$\vec{U}_{(h, k)}^{G}$ & Vector of system voltage at iteration $k$ and time $h$. \\
$\vec{U}_{(h, k, y)}^{G}$ & Vector of system voltage at iteration $k$, time $h$ and scenario $y$. \\
$\overrightarrow{\Delta U}_{(h, k)}^{G}$ & Vector of voltage reduction during iteration $k$ at time $h$. \\
$\overrightarrow{\Delta U}_{(h, k, y)}^{G}$ & Vector of voltage reduction during iteration $k$ at time $h$ and scenario $y$. \\
$\delta_{F}$ & Density of diesel fuel (kg/m ${ }^{3}$ ). \\
$\pi_{p}(y)$ & Probability of occurrence of scenario $y$. \\
&
\end{tabular}

\section{Introduction}

Depletion of natural resources and the impact of industrial activities on the ecosystem have given rise to societal measures to reduce the negative environmental consequences of human lifestyles and manufacturing processes.

In the context of energy systems (ESs), deployment of demand response (DR) resources and the implementation of smart grids (SGs) have gained interest due to their ability to incentivize active consumer participation. However, successful implementation of DR programs strongly depends on individual market structure as well as knowledge and awareness from the end-users [1]. Even when the incorporation of DR resources can benefit the environment, the crucial factor for DR adoption is economic profitability [2].

In the literature, many approaches have been created to deal with the problem of DR-resource allocation, taking into consideration the uncertainty introduced by end-user behavior. Some of these techniques are briefly explained in subsection 1.1.

\subsection{Literature review}


Optimization techniques used for DR allocation can be broadly classified into classical and metaheuristic algorithms [3]. On one hand, employment of classical algorithms consists of implementing linear programming [4], nonlinear programming, mixed-integer linear programming [5-8] or mixed-integer nonlinear programming. On the other hand, implementation of metaheuristic techniques - such as particle swarm optimization, genetic algorithm (GA) [9], simulated annealing, and teaching learningbased optimization - depends on the structure and coding of the problem under analysis. In a general sense, the technique to be used depends on the characteristics of a specific problem and its mathematical formulation.

Recently, reinforcement and deep learning [10,11], Stackelberg game [12], distributed optimization [13], harmony search algorithm [14], multi-agent system [15] and stochastic programming [16-19], among others, have gained popularity in the last year, while electricity bills for residential and industrial consumers - as well as the stochastic nature of renewable power sources - remain among the most important barriers to implementing DR solutions.

Once the full picture of DR-implementation and recent trends on DR-resource allocation has been briefly presented, the scope and novelty of this work are explained in subsection 1.2.

\subsection{Paper contribution and structure}

Consumer willingness to enroll in DR programs is the key factor, explained by many studies as a loss of comfort. Recently published reports on this topic have revealed that residential consumer interest in direct load control (DLC) programs has been constantly increasing, specifically when the extent of household-appliances control is clearly explained to the consumer and the nullify option is available [20,21]. Moreover, the utility company's reputation or credibility also plays an important role in growing enrollment in DLC programs [22].

Based on the increasing popularity of these programs, this work presents a contract scheme to be signed by the end-users and utility operator. In the proposed scheme, a high amount of time frames for load management (load shifting) are available to consumers so that they can accept the time frame that best accommodates their interests. In other words, the proposed contractual scheme specifies the amount of load to be shifted through the day and the hours at which the corresponding load are supposed to be available. This information is accepted by the consumers so that potential negative impacts are well known in advance, allowing them to manage possible inconveniences.

In this way, a tradeoff between the success of DLC-program implementation and the loss of consumer comfort can be achieved by means of clear conditions in the DLCprogram specification, which increases the possibility of implementing a DLC-program successfully. In order to consider the nonlinear behavior of battery energy storage systems (BESSs) and their interactions with controllable loads, the optimization approach adopted in this work is based on metaheuristic techniques. Each operative option (connection time of controllable loads) is represented as the row of a general matrix, which allows us to represent many circumstances in a flexible manner. Among the types of metaheuristic algorithms, the integer-coded GA has been chosen as optimization approach because the coding used is based on selecting the appropriate row from a controllable-load matrix. As GA evaluation requires intensive computational 
resources, an initialization algorithm has been incorporated in order to guide the evaluation towards an effective solution.

The content of the manuscript is presented as follows: section 2 describes the structure of ES under study; section 3 explains the strategy employed to manage DLCprogram and ES; and section 4 discusses the proposed approach through analysis of a case study in the Virgin Islands. Finally, conclusions and remarks are discussed on section 5 .

\section{Model of energy system}

The ES structures considered in this paper are shown in Fig. 1, where conventional and renewable generation, BESS and distribution system (DS) are presented. This ES has smart capabilities, meaning that the power production of each element can be monitored and used by the energy management system (EMS) to determine the optimal usage of DR resources and power dispatch by other controllable devices. EMS takes information from ES in order to determine the optimal management of conventional generators, BESS and DLC programs. DR resources are assumed to be spread over the DS.

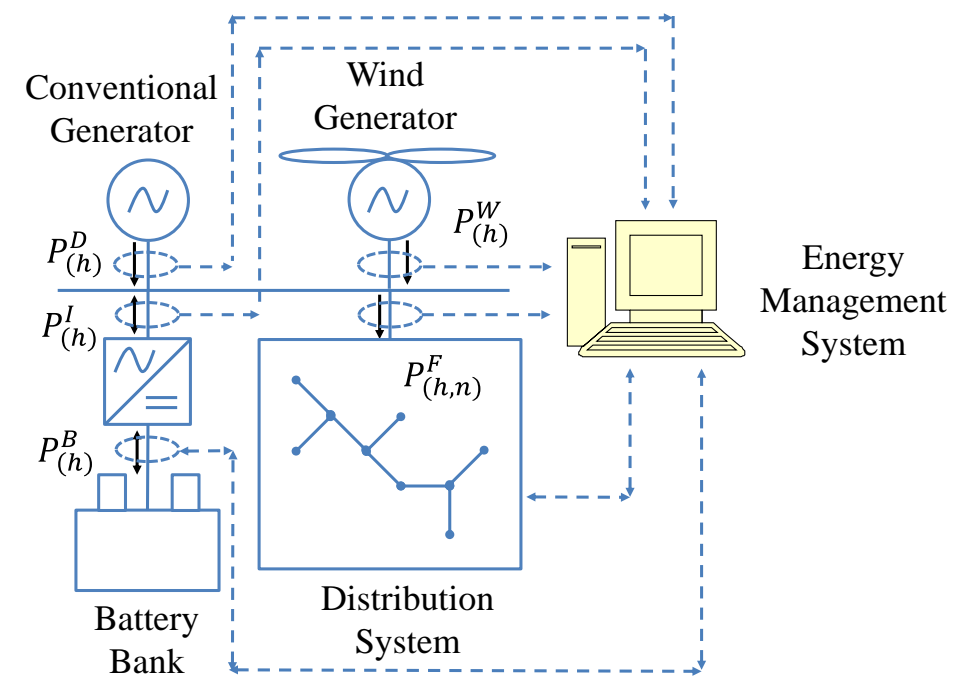

Fig. 1: Scheme of the energy system.

Regarding the model of the wind farm (WF), its power production is represented according to the general power curve developed in [23].

Regarding BESS and power converter, vanadium redox flow battery (VRFB) technology has been adopted due to growing interest on this technology. The VRFB model experimentally tested and published in [24-26] has been implemented; the rated power and energy of a single VRFB are $5 \mathrm{~kW}$ and $20 \mathrm{kWh}$, respectively. Using this information, a BESS of higher capacity can be built by connecting batteries in serial and parallel. The operation of a BESS is performed according to its charging $\left(P_{(h)}^{B}>0\right)$ and discharging $\left(P_{(h)}^{B}<0\right)$. The power converter has been modeled according to its efficiency curve as reported in [27].

Due to its applicability on islanded systems typically located in remote areas, the technology for conventional power production chosen in this work is diesel generation. Fuel consumption can be represented by means of a linear relationship with power 
generation. In addition, power generation has to be limited to determined values $\left(P_{r}^{D, \min }\right.$ and $P_{r}^{D, \max }$ ) recommended by the manufacturer.

The DS is modeled using the impedance of each branch of the system [28]. The voltage and current of each node and branch of the DS are defined in (1) and (2), while the load demand is defined according to the active and reactive power consumption.

$$
\begin{gathered}
\vec{U}_{(h, k)}^{G}=\left[\begin{array}{c}
U_{(h, k, 1)}^{G} \\
\vdots \\
U_{(h, k, n)}^{G} \\
\vdots \\
U_{(h, k, N)}^{G}
\end{array}\right] \ngtr h=1, \ldots, H ; k=1, \ldots, K ; \\
\vec{I}_{(h, k)}^{G}=\left[\begin{array}{c}
I_{(h, k, 1)}^{G} \\
\vdots \\
I_{(h, k, n)}^{G} \\
\vdots \\
I_{(h, k, N)}^{G}
\end{array}\right] \ngtr h=1, \ldots, H ; k=1, \ldots, K .
\end{gathered}
$$

Power flow through the DS is carried out using the forward-backward method [29], in which, the error defined in (3) is reduced.

$$
\Delta U_{G}=\sum_{n=1}^{N}|| U_{(h, k, n)}^{G}|-| U_{(h, k+1, n)}^{G}|| \ngtr h=1, \ldots, H ; k=1, \ldots, K .
$$

Once the voltage and current at each node and branch of DS have been determined, the ampacity violation can be verified by means of (4) [30], where the heat lost and gained by each feeder are estimated using daily forecasts of solar radiation, ambient temperature and wind speed.

$$
I_{(h, n)}^{G, \max }=\sqrt{\frac{P_{(h, n)}^{G, R}+P_{(h, n)}^{G, C}-P_{(h, n)}^{G, S}}{R_{(n)}}} \forall h=1, \ldots, H ; n=1, \ldots, N .
$$

\section{Management of DLC programs}

In order to describe the most important features of the proposed DLC program and consequently its management strategy, this section is devoted to explaining the characteristic of the proposed contractual scheme, as well as the algorithm for its management from a deterministic and probabilistic viewpoint. These three tasks are discussed in subsections 3.1, 3.2 and 3.3, respectively.

\subsection{DLC contract conditions}

Each customer classifies a load into two main categories: critical and controllable. A critical load has to be supplied at the moment required by the consumer, so this type cannot be directly controlled by the utility operator. Conversely, a controllable load can be managed by the utility operator through the DLC program 
following a rule previously agreed between the operator and the corresponding consumer connected to node $n$ of DS.

The concept used to model controllable loads is shown in Fig. 2 [31,32]. The function of the controllable load for a typical consumer connected to node $n$ and enrolled in DLC-contract $j$ is represented by means of an energy block with power $\Delta P_{(n)}^{L}$ and duration time $\Delta t_{(j)}$. As indicated in Fig. 2, the consumer is willing to use the corresponding device between the hours $t_{(j)}^{\min }$ and $t_{(j)}^{\max }$, starting at time $t_{(j)}$. The time intervals $\left[t_{(j)}^{\min }, t_{(j)}^{\max }\right]$ and $\Delta t_{(j)}$ are specified on the subscription contract $(j)$ signed between the consumer and the utility operator, while the power $\Delta P_{(n)}^{L}$ is specified by the consumer $n$.

The proposed approach optimizes the time at which controllable loads should start their operation $\left(t_{(j)}\right)$ in order to reduce the energy provided by controllable power sources (diesel generator and VRFB bank). Possible values of $t_{(j)}$ need to be considered during the optimization tasks, generally represented through the displacement of the energy block shown at the top of Fig. 2, and computationally expressed by using an equivalent matrix shown at the bottom of Fig. 2.
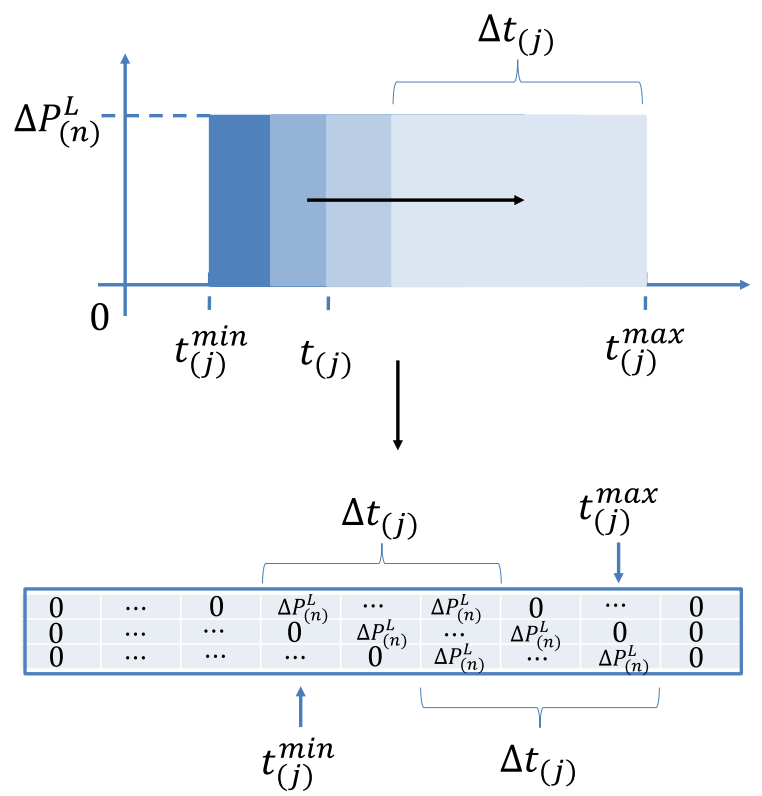

Fig. 2: Concept of possible demand curves table for contract $j$.

Fig. 3 shows the algorithm to build the matrix of possible demand curves $\left(P_{\left(m_{(j)}, h, j\right)}^{L}\right)$ for determined contract $j$, which was previously shown at the bottom of Fig. 2 . 


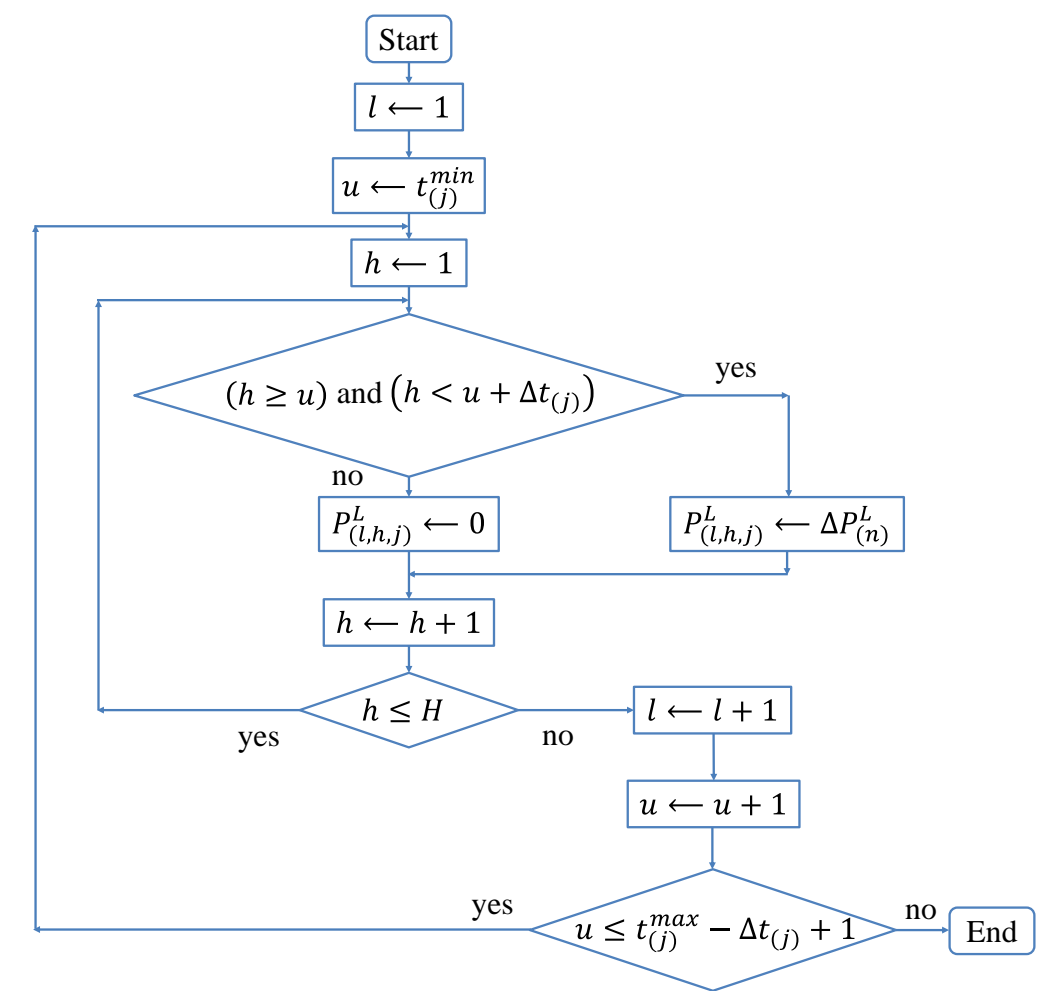

Fig. 3: Algorithm to build the possible demand curves table for contract $j$.

Fig. 4 describes the structure of the $P_{\left(m_{(j)}, h, j\right)}^{L}$ matrix, which has three different indexes. For a determined contract $(j)$, the first index $\left(m_{(j)}=1, \ldots, M_{(j)}\right)$ depends on the number of possible demand curves, which is between $m_{(j)}=1$ and $M_{(j)}=t_{(j)}^{\max }-$ $\Delta t_{(j)}+1$. The second index $(h=1, \ldots, H)$ represents the daytime, while the third index represent the type of DLC contract $(j=1, \ldots, J)$.

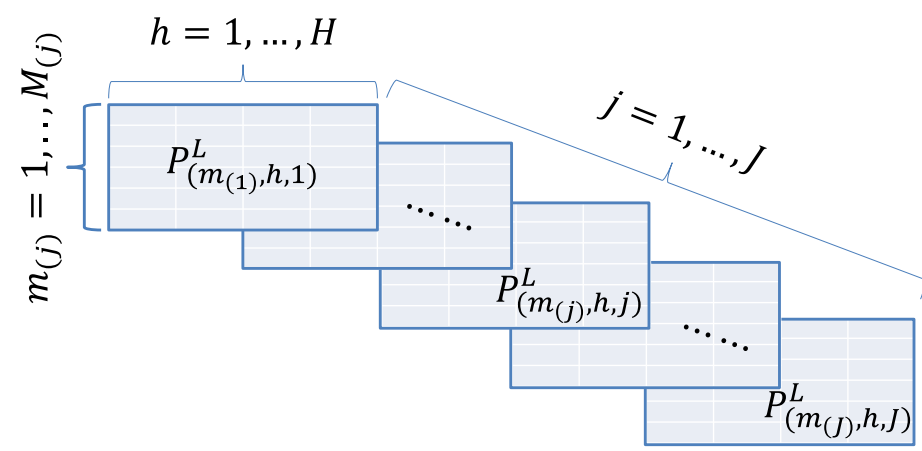

Fig. 4: Table of possible demand curves for all contracts.

Fig. 5 specifies some of the information to be agreed upon between each consumer and the utility operator. Each row on the table shown in Fig. 5 is a possible value of duration time $\left(\Delta t_{(j)}\right)$, earliest operation time $\left(t_{(j)}^{\min }\right)$ and the latest operation time $\left(t_{(j)}^{\max }\right)$ offered by the utility company. In this regard, the consumer voluntarily selects a determined row $(j)$ according to preference and convenience. Similarly, the power to be controlled $\left(\Delta P_{(n)}^{L}\right)$ is voluntarily chosen by the consumer and reported to the utility company on the subscription contract. 


\begin{tabular}{c|c|c|c|}
$j$ & $\Delta t_{(j)}$ & $t_{(j)}^{\min }$ & $t_{(j)}^{\max }$ \\
1 & 3 & 5 & 10 \\
2 & 6 & 1 & 24 \\
3 & 4 & 6 & 12 \\
$\vdots$ & $\vdots$ & $\vdots$ & $\vdots$ \\
$J-2$ & 2 & 10 & 15 \\
$J-1$ & 5 & 10 & 22 \\
$J$ & 3 & 8 & 23
\end{tabular}

Fig. 5: Table of contract definition.

Fig. 6 summarizes all the information to be used by the utility operator to control the DR program. The first column indicates the consumer (node $n$ of DS), while the second column $\left(C_{(n)}\right)$ indicates the type of contract in which the consumer is enrolled (row $j$ on Fig. 5). Finally, the third column indicates the controllable power $\left(\Delta P_{(n)}^{L}\right)$ agreed upon between the consumer and the utility company.

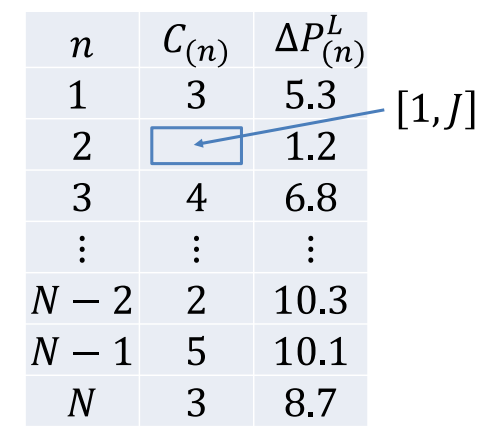

Fig. 6: Table of controllable loads.

Once the characteristics of the proposed DLC-contract structure have been defined, the methodology for allocating these resources should be specified. This task will be carried out under deterministic and probabilistic conditions in subsections 3.2 and 3.3 , respectively.

3.2. Optimal allocation of DR resources under total certainty of wind generation

Proper usage of DR resources available from users enrolled in the proposed DLC scheme is determined by solving the optimization problem shown in (5-18), where the first two expressions represent the variable to be optimized and the rest of the equations are the constraints related to the ES's physical limitations.

Equation (5) represents the objective to be minimized (6); this is the total energy obtained from diesel generator and VRFB bank. The first term is the energy contained in diesel fuel, while the second term specifically represents the energy obtained from VRFB during the discharging process.

These two terms are directly related to the operating cost of the system: diesel operating costs are directly related to the energy spent during the operation of the generator (first term in (5)), while the energy discharged from the BESS directly reduces its lifetime, which can be considered as an increment of the storage device's operating cost (second term in (5)).

Equation (7) specifies the balance at the substation level between power production from the diesel generator, WF, BESS and total load demand (including 
critical and controllable loads). Equations (8) and (9) are based on the model of controllable loads illustrated at the top of Fig. 2. These constraints guarantee the specifications of the contract type chosen by the corresponding user (subsection 3.1). Equations (10-14) are constraints related to the rated power and state of charge (SOC) limits of the VRFB bank, power converter and diesel generator. Constraints (15) and (16) guarantee the balance within the DS and are fully satisfied through the power flow solution (forward-backward method). Finally, constraints (17) and (18) are related to the ampacity and voltage limits.

$$
\begin{aligned}
& E_{S}=\sum_{h=1}^{H}\left(L H V_{F}\right)\left(\delta_{F}\right)\left(c_{1}^{O}\right) F_{(h)}^{D}+\sum_{h=1}^{H}\left(E_{r}^{B}\right)\left(\Delta S O C_{(h)}^{B}\right)\left(U_{(h)}^{B}\right) ; \\
& \min \left\{E_{S}\right\} ; \\
& -P_{(h)}^{D}+P_{(h, 1)}^{F}-P_{(h)}^{W}+P_{(h)}^{I}=0 \forall h=1, \ldots, H ; \\
& t_{(j)} \geq t_{(j)}^{\min } \forall j=1, \ldots, J \\
& t_{(j)}+\Delta t_{(j)} \leq t_{(j)}^{\max } \forall j=1, \ldots, J ; \\
& -P_{r}^{B} \leq P_{(h)}^{B} \leq P_{r}^{B} \forall h=1, \ldots, H ; \\
& -P_{r}^{I} \leq P_{(h)}^{I} \leq P_{r}^{I} \forall h=1, \ldots, H ; \\
& S O C_{\text {min }}^{B} \leq \operatorname{SOC}_{(h)}^{B} \leq S O C_{\text {max }}^{B} \forall h=1, \ldots, H \text {; } \\
& U_{\min }^{B} \leq U_{(h)}^{B} \leq U_{\text {max }}^{B} \forall h=1, \ldots, H \\
& P_{r}^{D, \min } \leq P_{(h)}^{D} \leq P_{r}^{D, \max } \\
& \overrightarrow{\Delta U}_{(h, K+1)}^{G}=[B C B V][B I B C] \vec{I}_{(h, K)}^{G} \ngtr h=1, \ldots, H ; \\
& \vec{U}_{(h, K+1)}^{G}=\overrightarrow{1}-\overrightarrow{\Delta U}_{(h, K+1)}^{G} \ngtr h=1, \ldots, H ; \\
& I_{(h, K, n)}^{G} \leq I_{(h, n)}^{G, \max } \forall h=1, \ldots, H ; n=1, \ldots, N ; \\
& U_{r}^{G, \min } \leq U_{(h, K, n)}^{G} \forall h=1, \ldots, H ; n=1, \ldots, N .
\end{aligned}
$$

The aforementioned solution to this problem consists of finding out the time $\left(t_{(j)}\right)$ at which the controllable load of each type of contract $(j)$ should be operated in order to minimize the energy $\left(E_{S}\right)$ obtained from the diesel fuel and VRFB bank.

It is possible to observe that time $t_{(j)}$ at the top of Fig. 2 is directly related to the rows of possible demand curves matrix $\left(P_{\left(m_{(j)}, h, j\right)}^{L}\right)$. This means that looking for the appropriate value of $t_{(j)}$ at the top of Fig. 2 is equivalent to looking for the appropriate row on the matrix $P_{\left(m_{(j)}, h, j\right)}^{L}$ at the bottom of Fig. 2. 
The optimization problem can be formulated as a search problem with integer variables, with these variables the corresponding row of the matrix $P_{\left(m_{(j)}, h, j\right)}^{L}$ for each contract type $j=1, \ldots, J$. Although controllable loads have been modeled using a constant power (Fig. 2), different power consumptions through time can be effectively represented because the optimization model only uses the corresponding row of the matrix. This characteristic allows us to consider realistic consumption profiles of household appliances and devices.

In this research, the optimization problem has been solved by using an integercoded GA. The structure of a typical individual $(r)$ is illustrated in Fig. 7: each individual is modeled as a vector $\left(\vec{a}_{(r)}\right)$, and each element of this vector $\left(a_{(r, j)}\right)$ is a row of the matrix $P_{\left(m_{(j)}, h, j\right)}^{L}$, so that $a_{(r, j)} \in\left[1, M_{(j)}\right]$.

$$
\vec{a}_{(r) \rightarrow \frac{a_{(r, j)} \in\left[1, M_{(j)}\right]}{\square}}
$$

Fig. 7: Structure of each individual.

The objective function $(\mathrm{Obj})$ previously shown in (5) has been reformulated in (19-22) to incorporate the DS's operating limits related to ampacity and voltage profile, as well as to avoid the energy not supplied (ENS). ENS is directly related to the power imbalance resulting from the system's lack of capacity to fulfill the constraint (7).

$$
\begin{gathered}
\text { obj }=E_{S}\left(1+\sum_{h=1}^{H} \sum_{n=1}^{N}\left\{T_{(h, n)}^{I}+T_{(h, n)}^{U}\right\}+\sum_{h=1}^{H} T_{(h)}^{E N S}\right) ; \\
T_{(h, n)}^{I}=\left\{\begin{array}{l}
0 ; I_{(h, K, n)}^{G} \leq I_{(h, n)}^{G, \max } 1 ; I_{(h, K, n)}^{G}>I_{(h, n)}^{G, \max } \\
1, n h=1, \ldots, H ; n=1, \ldots, N ;
\end{array}\right. \\
T_{(h, n)}^{U}=\left\{\begin{array}{l}
0 ; U_{r}^{G, \min } \leq U_{(h, K, n)}^{G} \\
1 ; U_{r}^{G, \min }>U_{(h, K, n)}^{G}
\end{array} \forall h=1, \ldots, H ; n=1, \ldots, N ;\right. \\
T_{(h)}^{E N S}=\left\{\begin{array}{l}
0 ; E N S_{(h)} \\
1 ; E N S_{(h)}>0
\end{array} \forall h=1, \ldots, H .\right.
\end{gathered}
$$

The value of objective function (19) increases when constraints (17) and (18) are violated, reducing the fitness value for the controllable-load allocation under evaluation (individual $\vec{a}_{(r)}$ of GA).

The complexity of the DR-management problem has been demonstrated to be NP-hardness [33]. In the contract scheme proposed in this work, the number of possible combinations grows according to (23). The maximum number of possible combinations is obtained when $t_{(j)}^{\max } \rightarrow H$ and $\Delta t_{(j)} \rightarrow 1$, resulting in $H^{J}$. Considering that our problem is being solved on a daily basis $(H=24)$, the number of combinations potentially grows with the contract types following the function $24^{J}$. 


$$
\prod_{j=1}^{J} M_{(j)}=\prod_{j=1}^{J}\left\{t_{(j)}^{\max }-\Delta t_{(j)}+1\right\}
$$

The population of the implemented GA can be written as a matrix according to (24), while each row is an individual that can be represented according to (25). Each element of the matrix $A$ and the vector $\vec{a}_{(r)}$ are integers, since they represent a row of the matrix $P_{\left(m_{(j)}, h, j\right)}^{L}$.

$$
\begin{aligned}
& A=\left[\begin{array}{c}
\vec{a}_{(1)} \\
\vdots \\
\vec{a}_{(r)} \\
\vdots \\
\vec{a}_{(R)}
\end{array}\right] \\
& \vec{a}_{(r)}=\left[\begin{array}{lllll}
a_{(r, 1)} & \cdots & a_{(r, j)} & \cdots & a_{(r, J)}
\end{array}\right] \forall r=1, \ldots, R .
\end{aligned}
$$

Fig. 8 describes how to build the daily profile for each node $(n)$ from the information found in the GA-population $(A)$. This algorithm uses the information provided in the table of controllable loads (Fig. 6) to find the contract $(j)$ in which the consumer $(n)$ is enrolled and, according to the individual $\left(\vec{a}_{(r)}\right)$ under analysis, estimate the total load profile $\left(P_{(h, n)}^{P} \forall h=1, \ldots, H\right)$ by adding the controllable $\left(P_{\left(a_{(r, j)}, h, j\right)}^{L} \forall h=\right.$ $1, \ldots, H)$ and critical $\left(P_{(h, n)}^{S} \forall h=1, \ldots, H\right)$ loads.

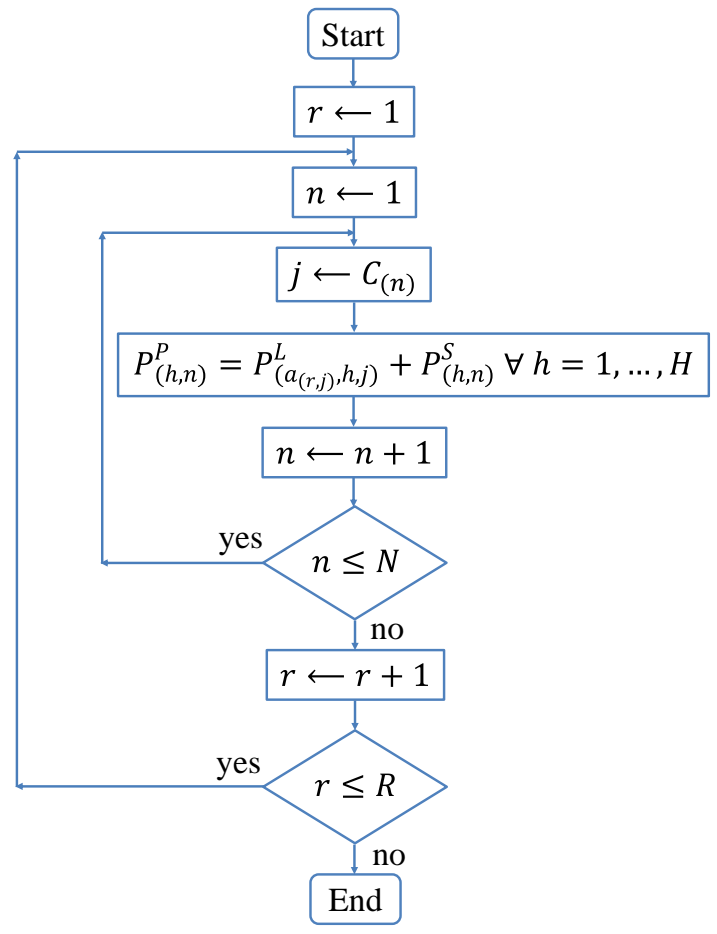

Fig. 8: Algorithm to build the daily load profile.

Once the total load at each node $n$ and time $h=1, \ldots, H$ has been calculated through matrix $P_{(h, n)}^{P}$, power flow analysis is carried out, obtaining the active power 
provided by the substation at branch $n=1\left(P_{(h, 1)}^{F}\right)$. This power value is later used to control the VRFB bank and diesel generator.

In this regard, the operation of the BESS depends on the value of net load $\left(P_{(n)}^{N L}\right)$, which is defined in (26) as the subtraction of the active power demand $\left(P_{(h, 1)}^{F}\right)$ from the power production of $\mathrm{WF}\left(P_{(h)}^{W}\right)$. According to this energy policy, renewable generation has the highest priority, which guarantees the consumption of clean energy.

$$
P_{(h)}^{N L}=P_{(h, 1)}^{F}-P_{(h)}^{W}
$$

The VRFB bank is controlled by using a cycle charging strategy [34]. In this strategy, part of the excess energy produced by the diesel generator is stored in the BESS, improving its operating efficiency when the load demand is low.

Fig. 9 describes how the cycle-charging strategy is implemented in this paper. Depending on the energy stored in the VRFB bank, it is first determined whether the power is enough to supply total demand. If this is possible, then the VRFB bank is discharged; if not, it is evaluated whether a diesel generator would be required or not. If upon discharging the VRFB bank the power to be supplied by the diesel generator is lower than its minimum $\left(P_{r}^{D, \min }\right)$, an excess of energy would be produced; to avoid this condition, the VRFB bank is then charged. If this is not the case, discharging the VRFB bank is suggested.

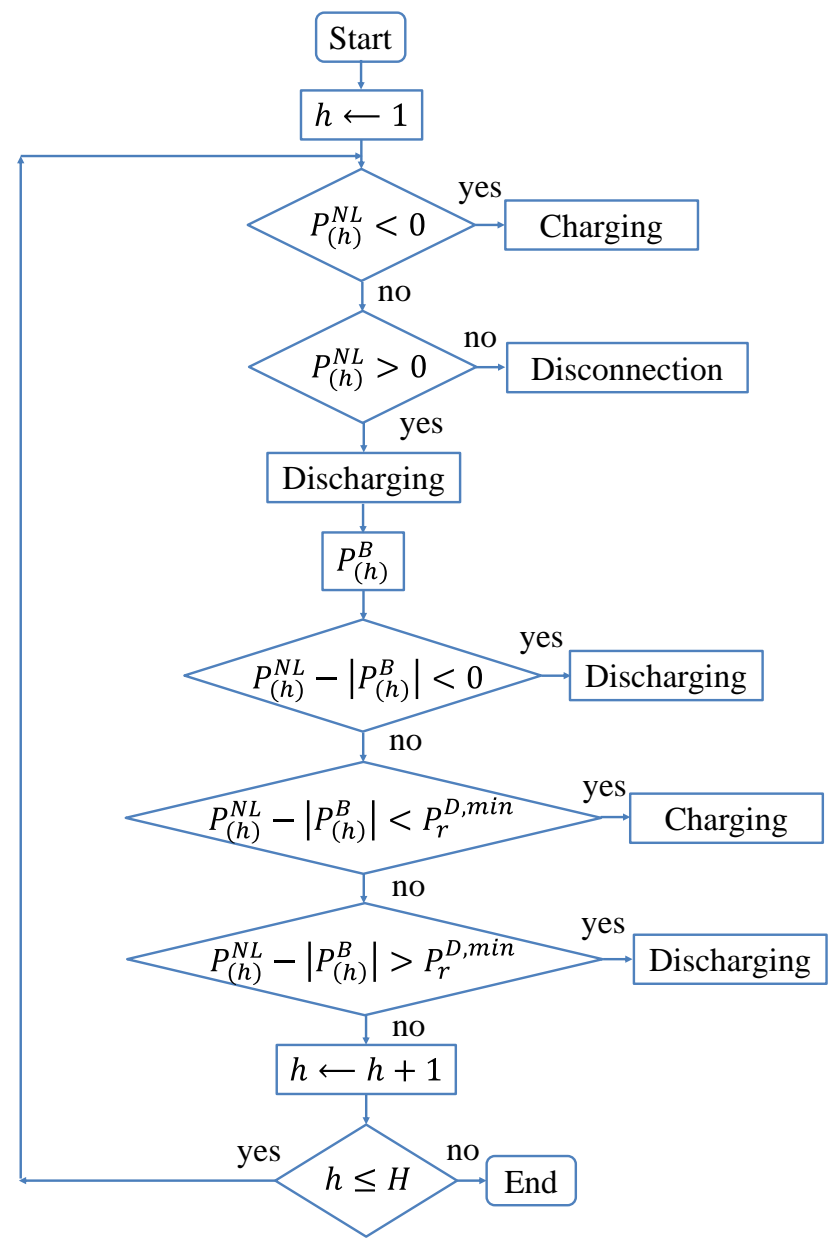

Fig. 9: Algorithm to control BESS. 
If the power to be supplied by the generator is within the interval $\left[P_{r}^{D, \min }, P_{r}^{D, \max }\right]$, the generator is assumed to be connected and a linear relationship is used to estimate fuel consumption, which is necessary to calculate the objective to be minimized $(5,6)$. On the other hand, if the power to be supplied by the generator is lower than the minimum $\left(P_{r}^{D, m i n}\right)$, the generator is assumed to be connected, storing the excess of energy in a VRFB bank. Finally, if the generator is not required, then it is assumed to be disconnected.

So far, the complete evaluation of a single individual $\left(\vec{a}_{(r)}\right)$ of the GA population $(A)$ has been described. Other processes, such as reproduction, crossing, and mutation, are well known in the technical literature; further details about the integer-coded GA implementation can be found in [35].

\subsection{Optimal allocation of DR resources under uncertainty of wind generation}

The procedure described in subsection 3.2 strongly depends on the quality of available wind-power forecasting. In order to mitigate the effects of wind-power uncertainty, scenario generation and reduction processes have been adopted.

For a determined number of scenarios $(y=1, \ldots, Y)$, the starting time for each contract type $\left(t_{(j)} \forall j=1, \ldots, J\right)$ can be determined by solving the optimization problem of (27-40). Equation (27) represents the energy related to each controllable source for a determined scenario $y$. According to (28), the optimization problem consists of minimizing the expected value of the energy obtained from the diesel generator and battery bank. Each scenario has an associated occurrence probability equal to $1 / Y$ $\left(\pi_{p}(y)=1 / Y \forall y=1, \ldots, Y\right)$. Constraints (29) and (31-40) represent the system's hourly behavior, which depends on each scenario.

The solution of the optimization problem consists of finding the starting time $\left(t_{(j)} \forall j=1, \ldots, J\right)$ that minimizes the expected value of the energy obtained from each controllable power source. Under the uncertain conditions introduced by wind generation, it is necessary to allocate controllable loads in an optimal manner regardless of any wind-power scenario; this is why starting time $(30,31)$ is the same for all situations under consideration.

$$
\begin{gathered}
E_{S(y)}=\sum_{h=1}^{H}\left(L H V_{F}\right)\left(\delta_{F}\right)\left(c_{1}^{O}\right) F_{(h, y)}^{D}+\sum_{h=1}^{H}\left(E_{r}^{B}\right)\left(\Delta S O C_{(h, y)}^{B}\right)\left(U_{(h, y)}^{B}\right) ; \\
\min \left\{\sum_{y=1}^{Y} \pi_{p}(y) E_{S(y)}\right\} ; \\
-P_{(h, y)}^{D}+P_{(h, 1, y)}^{F}-P_{(h, y)}^{W}+P_{(h, y)}^{I}=0 \forall h=1, \ldots, H ; y=1, \ldots, Y ; \\
t_{(j)} \geq t_{(j)}^{\min } \forall j=1, \ldots, J ; \\
t_{(j)}+\Delta t_{(j)} \leq t_{(j)}^{\max } \forall j=1, \ldots, J ; \\
-P_{r}^{B} \leq P_{(h, y)}^{B} \leq P_{r}^{B} \forall h=1, \ldots, H ; y=1, \ldots, Y ;
\end{gathered}
$$




$$
\begin{gathered}
-P_{r}^{I} \leq P_{(h, y)}^{I} \leq P_{r}^{I} \forall h=1, \ldots, H ; y=1, \ldots, Y ; \\
S O C_{\min }^{B} \leq S O C_{(h, y)}^{B} \leq S O C_{\max }^{B} \forall h=1, \ldots, H ; y=1, \ldots, Y ; \\
U_{\min }^{B} \leq U_{(h, y)}^{B} \leq U_{\max }^{B} \forall h=1, \ldots, H ; y=1, \ldots, Y ; \\
P_{r}^{D, \min } \leq P_{(h, y)}^{D} \leq P_{r}^{D, \max } ; h=1, \ldots, H ; y=1, \ldots, Y ; \\
\overrightarrow{\Delta U}_{(h, K+1, y)}^{G}=[B C B V][B I B C] \vec{I}_{(h, K, y)}^{G} \forall h=1, \ldots, H ; y=1, \ldots, Y ; \\
\vec{U}_{(h, K+1, y)}^{G}=\overrightarrow{1}-\overrightarrow{\Delta U}_{(h, K+1, y)}^{G} \forall h=1, \ldots, H ; y=1, \ldots, Y ; \\
I_{(h, K, n, y)}^{G} \leq I_{(h, n, y)}^{G, \max } \forall h=1, \ldots, H ; n=1, \ldots, N ; y=1, \ldots, Y ; \\
U_{r}^{G, \min } \leq U_{(h, K, n, y)}^{G} \forall h=1, \ldots, H ; n=1, \ldots, N ; y=1, \ldots, Y .
\end{gathered}
$$

The integer-coded GA described in subsection 3.2 can be used to solve the problem (27-40), considering the formulation of the objective function shown in (41$44)$. In this formulation, the influence of each scenario on ampacity and ENS is taken into account.

$$
\begin{aligned}
& O b j=\sum_{y=1}^{Y}\left\{\pi_{p}(y) E_{S(y)}\left(1+\sum_{h=1}^{H} \sum_{n=1}^{N}\left\{T_{(h, n, y)}^{I}+T_{(h, n, y)}^{U}\right\}+\sum_{h=1}^{H} T_{(h, y)}^{E N S}\right)\right\} ; \\
& T_{(h, n, y)}^{I}=\left\{\begin{array}{l}
0 ; I_{(h, K, n, y)}^{G} \leq I_{(h, n, y)}^{G, \max } \\
1 ; I_{(h, K, n, y)}^{G}>I_{(h, n, y)}^{G, \max }
\end{array} \forall h=1, \ldots, H ; n=1, \ldots, N ; y=1, \ldots, Y ;\right. \\
& T_{(h, n, y)}^{U}=\left\{\begin{array}{l}
0 ; U_{r}^{G, \min } \leq U_{(h, K, n, y)}^{G} \\
1 ; U_{r}^{G, \text { min }}>U_{(h, K, n, y)}^{G}
\end{array} \forall h=1, \ldots, H ; n=1, \ldots, N ; y=1, \ldots, Y ;\right. \\
& T_{(h, y)}^{E N S}=\left\{\begin{array}{l}
0 ; E N S_{(h, y)}=0 \\
1 ; E N S_{(h, y)}>0
\end{array} \forall h=1, \ldots, H ; y=1, \ldots, Y .\right.
\end{aligned}
$$

In section 4, the proposed DLC-contract scheme and its optimal management are illustrated through a case study.

\section{Case study}

The proposed scheme for the DLC program is illustrated through analysis of a hybrid energy system (HES) located in the Virgin Islands (latitude $17.73^{\circ}$ and longitude $\left.-64.79^{\circ}\right)$. Information related to environmental variables such as solar radiation, wind speed and ambient temperature was taken from the public database found in [36-38]. Data related to the DS structure is presented in Table 1, using a system with 20 nodes $(N=20)$. The rated voltage of the DS was assumed to be $12.47 \mathrm{kV}$, while its frequency was assumed as $60 \mathrm{~Hz}$. The rated power of the substation was assumed as $350 \mathrm{kVA}$. A 
power flow analysis was performed using a tolerance of $0.001\left(\Delta U_{G} \leq 0.001\right)$ with a maximum of 10 iterations $(K \leq 10)$. A power factor of 0.95 was assumed for all the loads at any time. Constraints $(21,43)$ on the optimization problem were evaluated by considering $U_{r}^{G, \min }=0.95$ in per unit.

Table 1: DS information.

\begin{tabular}{ccccc}
\hline \multicolumn{2}{c}{ Network topology } & \multicolumn{3}{c}{ Distribution feeder information } \\
\hline $\begin{array}{c}\text { Sending } \\
\text { node }\end{array}$ & $\begin{array}{c}\text { Receiving } \\
\text { node }(n)\end{array}$ & kcmil & Strands & Length $(\mathrm{km})$ \\
\hline $\begin{array}{c}\text { Substation } \\
1\end{array}$ & 1 & 300 & 19 & 1.57 \\
2 & 2 & 300 & 19 & 1.21 \\
3 & 3 & 300 & 19 & 1.79 \\
4 & 4 & 300 & 19 & 2.60 \\
5 & 5 & 300 & 19 & 1.49 \\
6 & 6 & 300 & 19 & 1.11 \\
7 & 7 & 300 & 19 & 1.17 \\
8 & 8 & 300 & 19 & 2.18 \\
9 & 9 & 300 & 19 & 1.39 \\
1 & 10 & 300 & 19 & 1.03 \\
2 & 11 & 26.24 & 7 & 2.66 \\
3 & 12 & 26.24 & 7 & 2.75 \\
4 & 13 & 26.24 & 7 & 1.35 \\
5 & 14 & 26.24 & 7 & 1.64 \\
6 & 15 & 26.24 & 7 & 2.04 \\
7 & 16 & 26.24 & 7 & 2.18 \\
8 & 17 & 26.24 & 7 & 1.31 \\
9 & 18 & 26.24 & 7 & 2.55 \\
10 & 19 & 26.24 & 7 & 1.68 \\
& 20 & 26.24 & 7 & 1.90 \\
\hline
\end{tabular}

The specific conditions of the DLC-contract scheme are shown in Table 2, where 10 different contract types $(J=10)$ have been considered.

Table 2: Contract definition for case study.

\begin{tabular}{cccc}
\hline$j$ & $\Delta t_{(j)}$ & $t_{(j)}^{\min }$ & $t_{(j)}^{\max }$ \\
\hline 1 & 2 & 9 & 16 \\
2 & 2 & 16 & 20 \\
3 & 1 & 14 & 20 \\
4 & 2 & 1 & 10 \\
5 & 1 & 12 & 24 \\
6 & 3 & 16 & 20 \\
7 & 3 & 7 & 11 \\
8 & 3 & 1 & 24 \\
9 & 2 & 7 & 11 \\
10 & 2 & 1 & 24 \\
\hline
\end{tabular}

The proposed optimization algorithm was implemented in a personal computer with i7-3630QM CPU at $2.4 \mathrm{GHz}, 8 \mathrm{~GB}$ of memory and a 64-bit operating system. The computing language used was MATLAB $\odot$. 
4.1. Management of DLC programs under total certainty of wind generation

In this subsection, wind generation is considered under perfect forecasting. For this condition, the contract in which each consumer is enrolled $\left(C_{(n)}\right)$, as well as the value of controllable power $\left(\Delta P_{(n)}^{L}\right)$ shown in Table 3.

Table 3: Controllable loads for case study.

\begin{tabular}{ccc}
\hline$n$ & $C_{(n)}$ & $\Delta P_{(n)}^{L}$ \\
\hline 1 & 1 & 11.19 \\
2 & 8 & 11.89 \\
3 & 3 & 11.07 \\
4 & 2 & 10.61 \\
5 & 4 & 10.05 \\
6 & 7 & 11.65 \\
7 & 5 & 11.23 \\
8 & 6 & 10.09 \\
9 & 9 & 11.01 \\
10 & 4 & 12.30 \\
11 & 1 & 12.01 \\
12 & 10 & 11.01 \\
13 & 8 & 11.72 \\
14 & 5 & 10.89 \\
15 & 2 & 11.47 \\
16 & 9 & 11.75 \\
17 & 6 & 11.05 \\
18 & 2 & 11.35 \\
19 & 3 & 12.60 \\
20 & 1 & 10.96 \\
\hline
\end{tabular}

Fig. 10 presents the daily profile of a critical load over the entire system. This profile has to be supplied by the utility company without considering any DR management strategy and was created using data taken from [39]. 


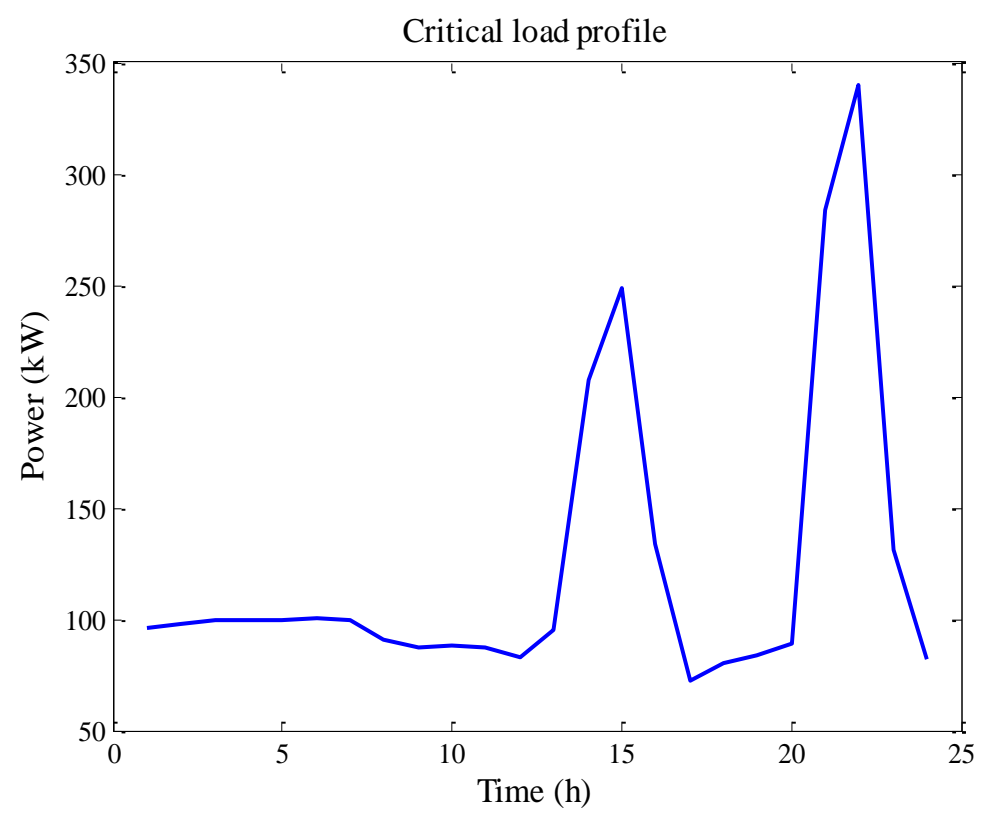

Fig. 10: Daily critical load profile.

In the VRFB bank, the SOC $\left(S O C_{(h)}^{B}\right)$ was kept to be between $15 \%$ $\left(S O C_{\min }^{B}=0.15\right)$ and $90 \%\left(S O C_{\max }^{B}=0.9\right)$, while battery voltage was kept between $42 \mathrm{~V}$ $\left(U_{\text {min }}^{B}=42 \mathrm{~V}\right)$ and $56.5 \mathrm{~V}\left(U_{\max }^{B}=56.5 \mathrm{~V}\right)$. The battery bank was built by connecting 10 batteries in serial and 10 in parallel, and the initial SOC was set to its minimum allowed value $\left(\operatorname{SOC}_{(0)}^{B}=0.15\right)$.

The WF was assumed to be built by only one turbine of $150 \mathrm{~kW}$. A diesel generator of $350 \mathrm{~kW}\left(P_{r}^{D, \max }=350 \mathrm{~kW}\right)$ was considered, its minimum output power assumed to be $25 \%$ of its rated capacity $\left(P_{r}^{D, \min }=0.25\left[P_{r}^{D, \max }\right]\right)$. The linear fuel consumption pattern was built by considering 7.9 gal of diesel consumption at $1 / 4$ of the load, $13.1 \mathrm{gal}$ of diesel consumption at $1 / 2$ the load, $18.7 \mathrm{gal}$ of diesel consumption at $3 / 4$ load and 25.1 gal of diesel consumption at full load. Regarding the estimation of the objective function, fuel density was considered $820 \mathrm{~kg} / \mathrm{m}^{3}\left(\delta_{F}=820 \mathrm{~kg} / \mathrm{m}^{3}\right)$, and the low heating value was considered as $43.2 \mathrm{MJ} / \mathrm{kg}\left(L H V_{F}=43.2 \mathrm{MJ} / \mathrm{kg}\right)$.

The DLC-contract scheme performance has been evaluated for the first day of January as well as the entire year.

Figs. 11, 12, and 13 show the wind speed, ambient temperature and solar radiation, respectively, for the first day of January. Wind speed is used to estimate wind power and it is used jointly with solar radiation and temperature on the ampacity evaluation of each DS feeder according to (4). 


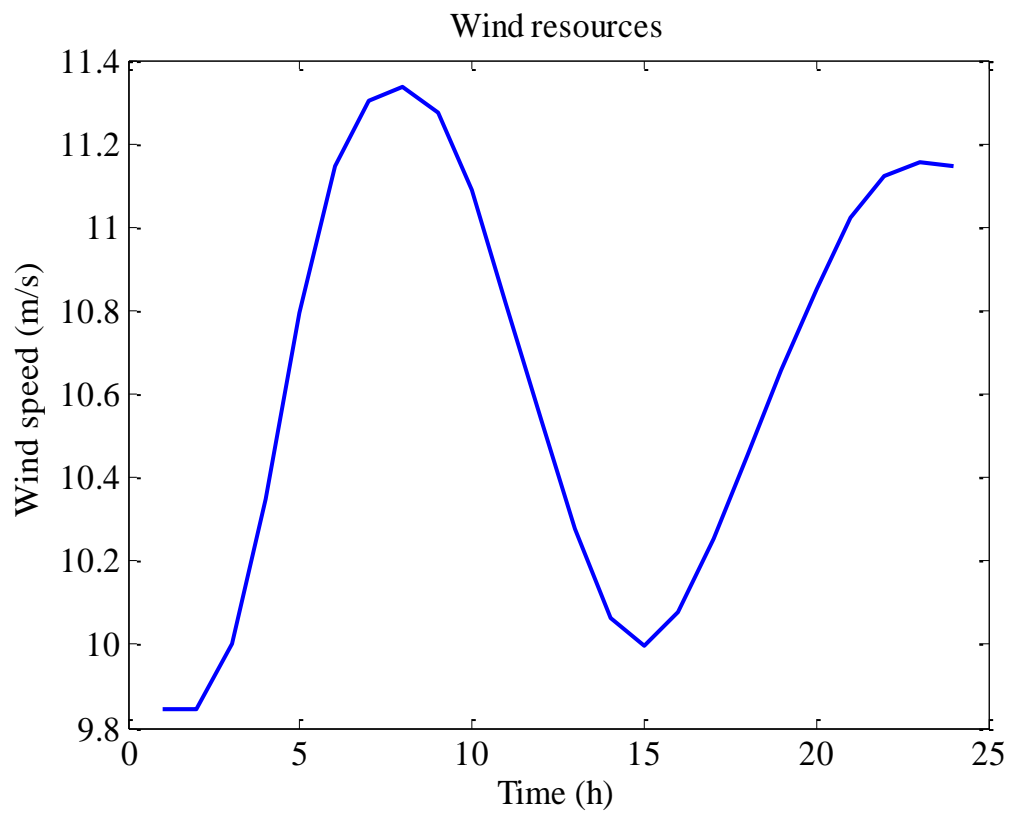

Fig. 11: Wind speed profile.

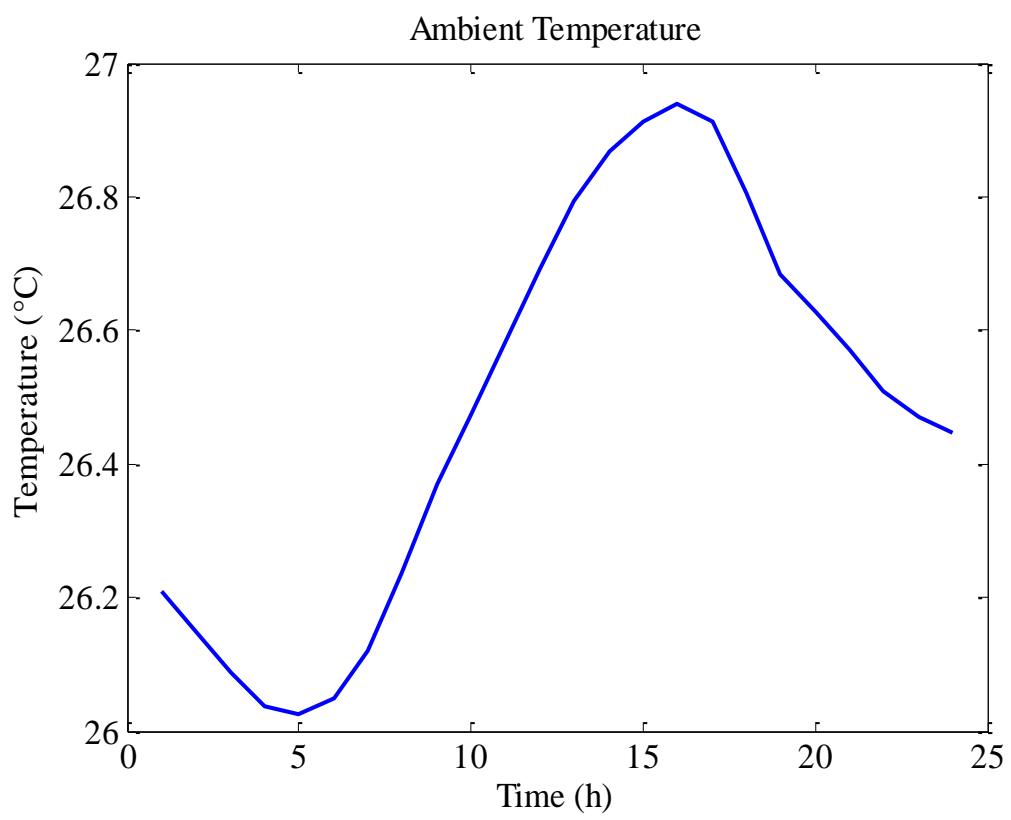

Fig. 12: Ambient temperature. 


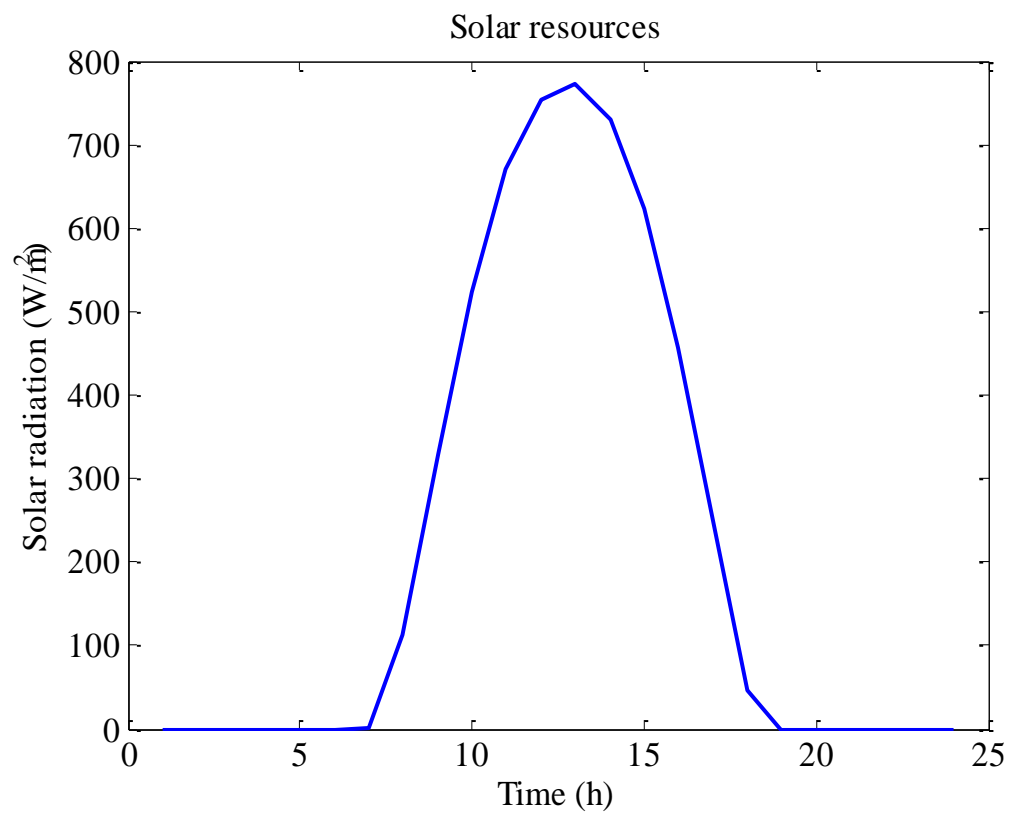

Fig. 13: Solar radiation.

The proposed GA explored in subsection 3.2 was implemented using 80 individuals, 150 generations, crossover rate of $95 \%$, and $5 \%$ of mutation rate. Fig. 14 presents the evolution of GA for DR-resource allocation.

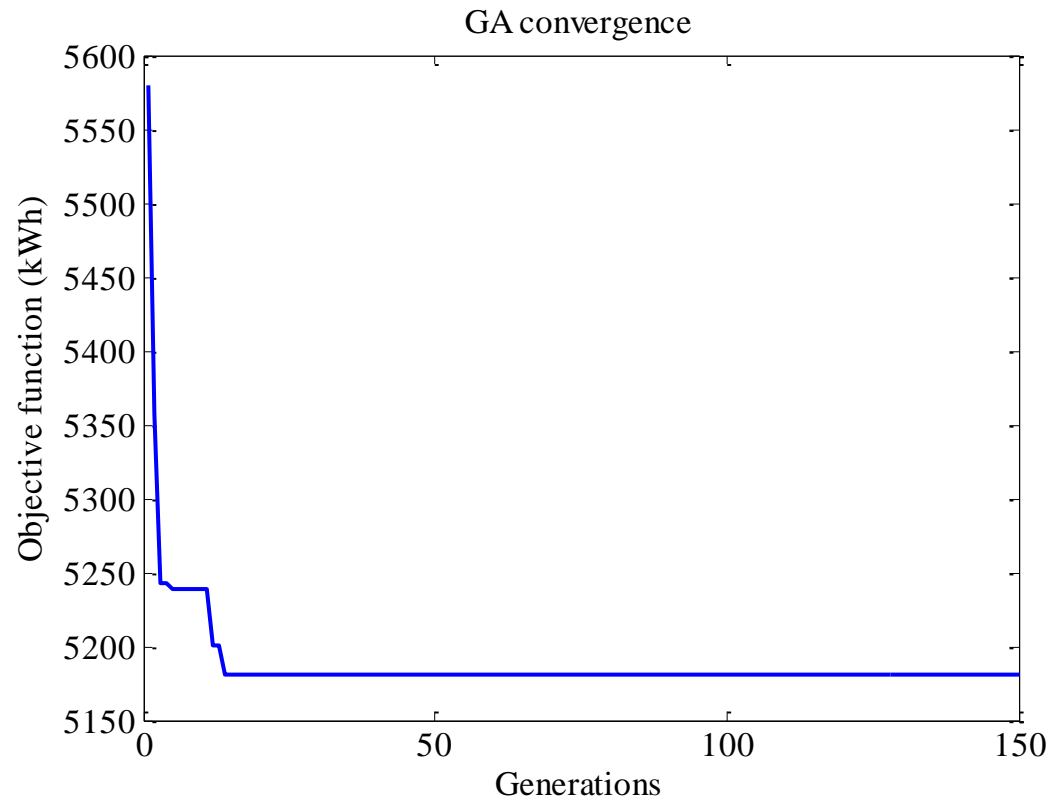

Fig. 14: GA evolution (Deterministic optimization).

On one hand, Fig. 15 shows how controllable loads should be used. Controllable loads are operated according to the conditions of the corresponding contract scheme in order to reduce the power delivered by the controllable power sources (Fig. 14). Most of the controllable loads are operated between $h=4$ and $h=9$, and between $h=15$ and $h=19$ where wind speed is expected to be high (Fig. 11). 


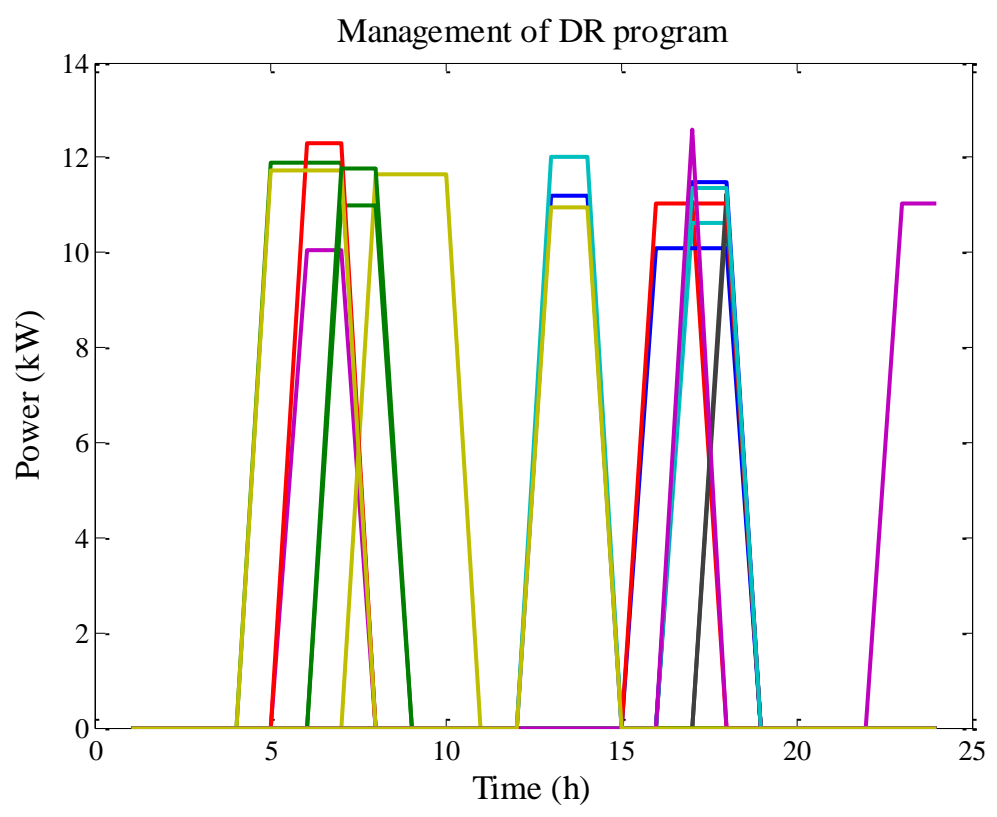

Fig. 15: Allocation of DLC resources (Deterministic optimization).

On the other hand, Figs. 16 and 17 present the performance of HES. During the first hour $(h=1)$, the conventional generator is committed to its minimum power in order to supply part of the load and charge the VRFB. At $h=2$, renewable generation and the VRFB discharging power provide enough to supply load demand, so that the conventional generator is disconnected. At $h=3$, load demand lightly increases, requiring the production of conventional generation. Thus, energy surplus is used to charge the battery bank. From $h=4$, load demand starts increasing; hence, power discharged from the VRFB is specifically required to supply energy demand between $h=4$ and $h=5$. From $h=6$ to $h=13$, the VRFB is continuously charged using the energy surplus from wind generation, as well as the excess generated by the conventional unit. From $h=14$ to $h=15$, the battery bank is discharged, while the conventional unit increases its power production to supply the peak load. From $h=16$ to $h=20$, the battery bank is continuously charged by using the excess power available from wind and conventional generation. Later, part of this energy is used to supply the energy demand between $h=21$ and $h=23$, while the conventional unit increases its power generation to cover the peak load. Finally, the battery bank is recharged at $h=24$, when load demand decreases. 


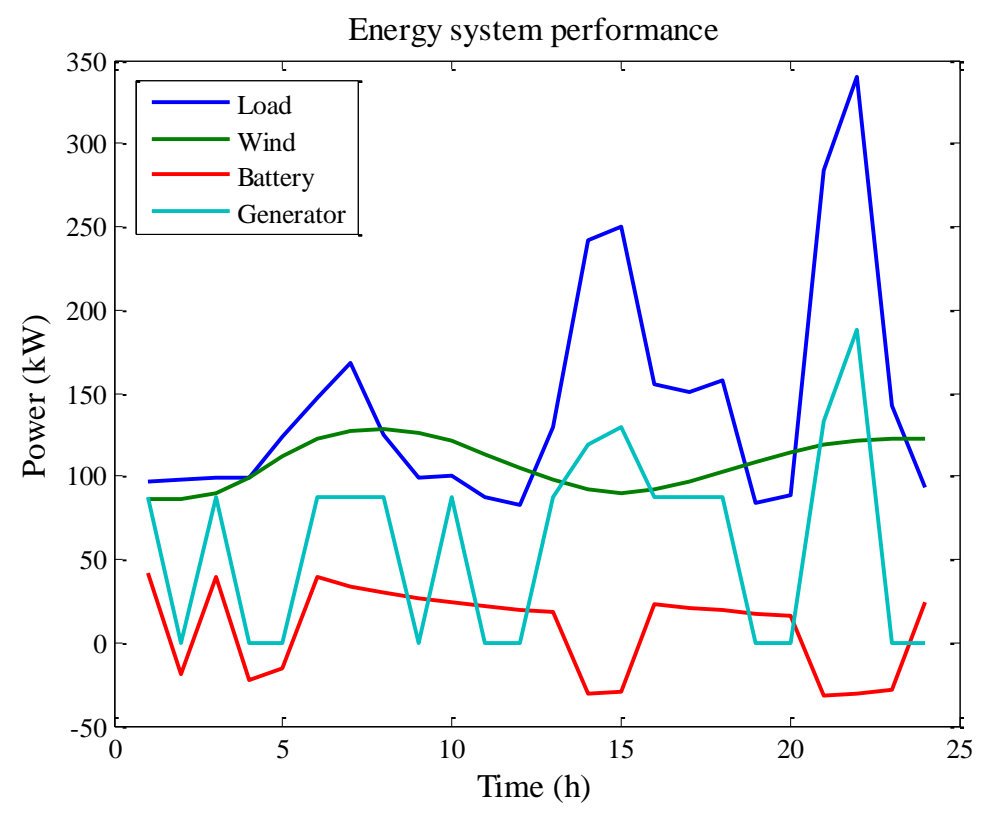

Fig. 16: General performance of HES.

Fig. 17 shows how SOC largely increases between $h=6$ and $h=13$, reaching $72.82 \%$, to be later discharged during the peak-load time.

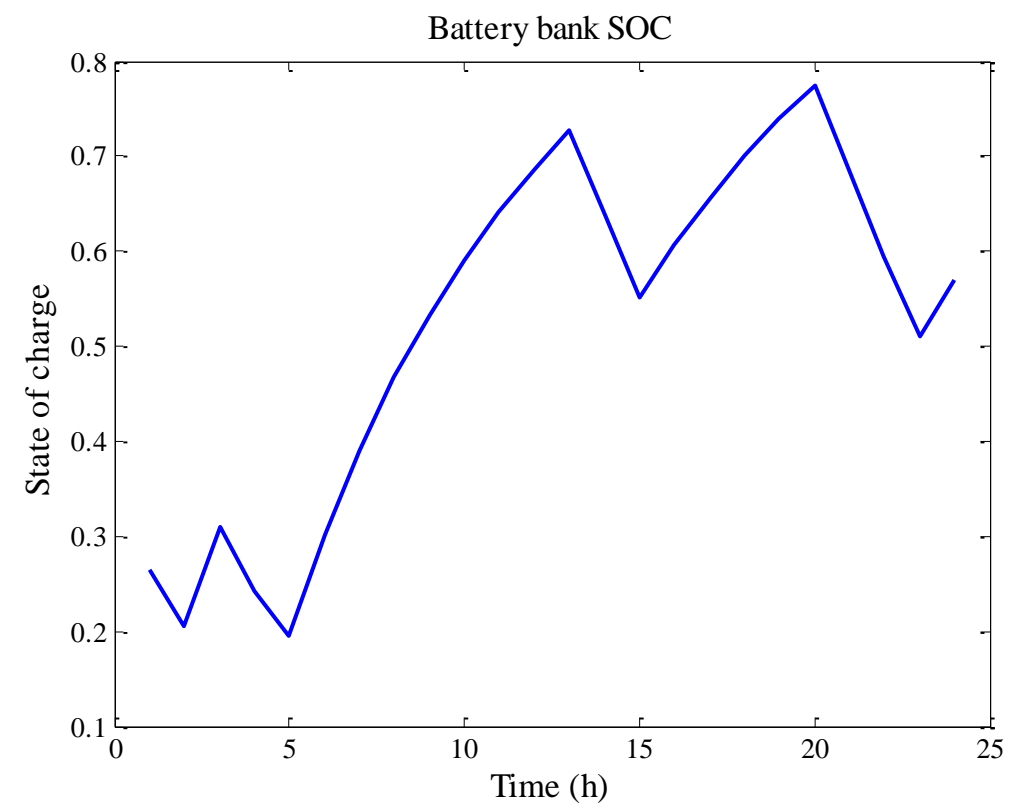

Fig. 17: SOC profile (Deterministic optimization).

Figs. 18 and 19 show the behavior of the DS's voltage and current profiles. As the rated voltage was assumed to be high $(12.47 \mathrm{kV})$ and the load profile was relatively low, the expected voltage and current variations are very low. Categories established on the color bars are related to the load level, reporting voltage, current, nodes, time and load level. 


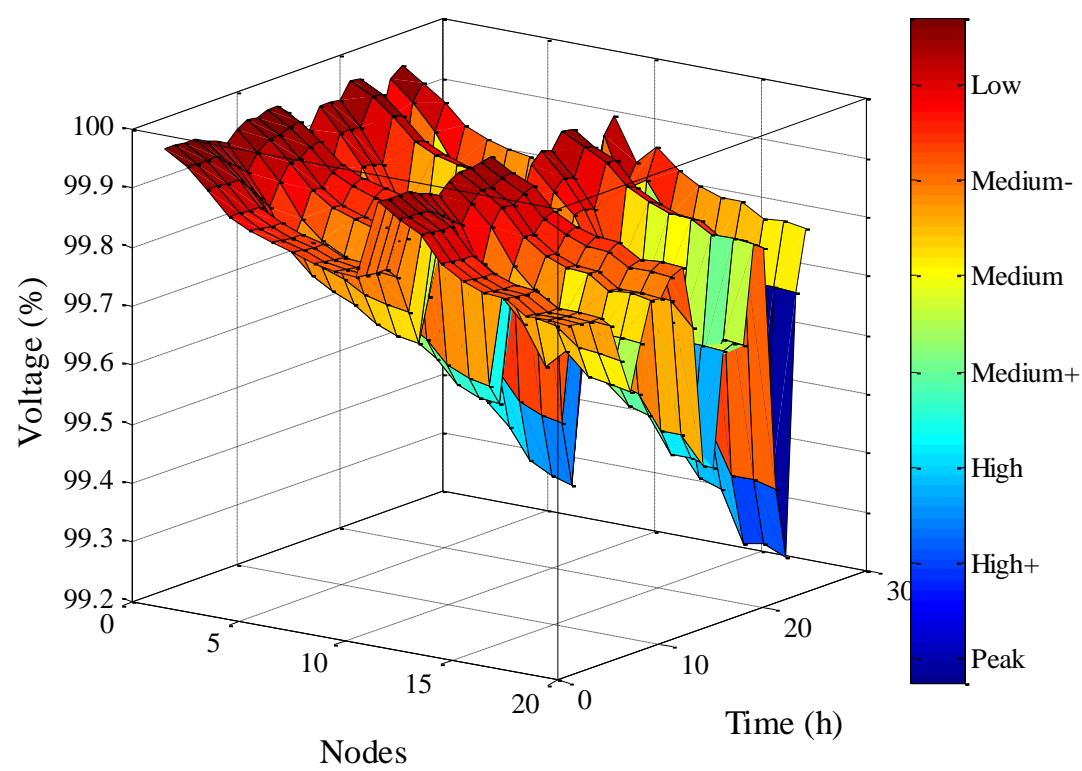

Fig. 18: Voltage profile.

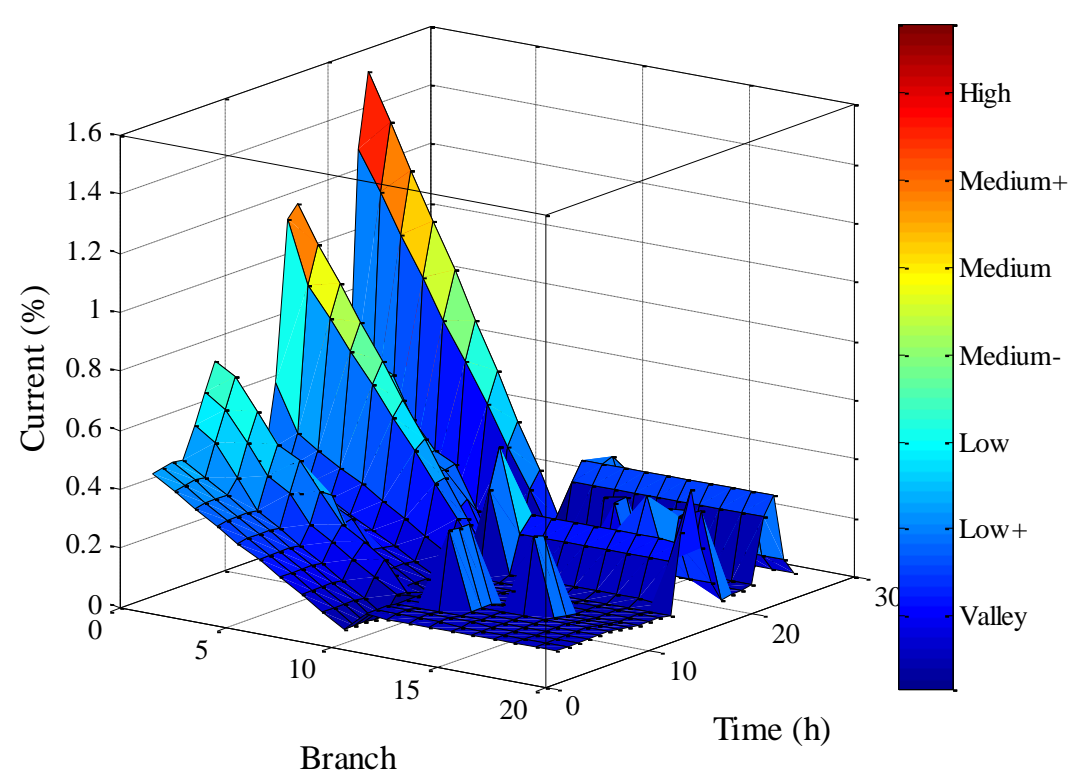

Fig. 19: Current profile.

Table 4 summarizes the most important results obtained during one day and one year of operation. Under base operation, enrollment in the proposed DLC program, as well as WF and BESS operations, are not considered. In this regard, load demand is satisfied only using diesel generation.

Table 4: Allocation of DLC resources for deterministic-daily analysis.

\begin{tabular}{|c|c|c|c|c|c|}
\hline \multirow[b]{2}{*}{$n$} & \multirow{2}{*}{$\begin{array}{l}t_{(j)}^{\min } \forall \\
j=C_{(n)}\end{array}$} & \multirow{2}{*}{$\begin{array}{l}t_{(j)}^{\max } \forall \\
j=C_{(n)}\end{array}$} & \multicolumn{2}{|c|}{$t_{(j)} \forall C_{(n)}$ (Optimized operation) } & \multirow{2}{*}{$\begin{array}{c}t_{(j)} \forall j=C_{(n)} \\
\text { (Base operation) }\end{array}$} \\
\hline & & & One day & One year & \\
\hline 1 & 9 & 16 & 13 & $11.0 \mathrm{~h} \pm 10.3 \%$ & 13 \\
\hline 2 & 1 & 24 & 5 & $7.40 \mathrm{~h} \pm 85.6 \%$ & 13 \\
\hline 3 & 14 & 20 & 17 & $18.0 \mathrm{~h} \pm 7.10 \%$ & 14 \\
\hline
\end{tabular}




\begin{tabular}{cccccc}
\hline 4 & 16 & 20 & 17 & $17.7 \mathrm{~h} \pm 5.30 \%$ & 16 \\
5 & 1 & 10 & 6 & $4.30 \mathrm{~h} \pm 63.6 \%$ & 9 \\
6 & 7 & 11 & 8 & $8.00 \mathrm{~h} \pm 10.7 \%$ & 9 \\
7 & 12 & 24 & 18 & $20.1 \mathrm{~h} \pm 21.7 \%$ & 12 \\
8 & 16 & 20 & 16 & $17.3 \mathrm{~h} \pm 3.80 \%$ & 16 \\
9 & 7 & 11 & 7 & $8.50 \mathrm{~h} \pm 13.6 \%$ & 10 \\
10 & 1 & 10 & 6 & $4.30 \mathrm{~h} \pm 63.6 \%$ & 9 \\
11 & 9 & 16 & 13 & $11.0 \mathrm{~h} \pm 10.3 \%$ & 13 \\
12 & 1 & 24 & 23 & $10.1 \mathrm{~h} \pm 71.4 \%$ & 20 \\
13 & 1 & 24 & 5 & $7.40 \mathrm{~h} \pm 85.6 \%$ & 13 \\
14 & 12 & 24 & 18 & $20.1 \mathrm{~h} \pm 21.7 \%$ & 12 \\
15 & 16 & 20 & 17 & $17.7 \mathrm{~h} \pm 5.30 \%$ & 16 \\
16 & 7 & 11 & 7 & $8.50 \mathrm{~h} \pm 13.6 \%$ & 10 \\
17 & 16 & 20 & 16 & $17.30 \mathrm{~h} \pm 3.8 \%$ & 16 \\
18 & 16 & 20 & 17 & $17.70 \mathrm{~h} \pm 5.3 \%$ & 16 \\
19 & 14 & 20 & 17 & $18.00 \mathrm{~h} \pm 7.1 \%$ & 14 \\
20 & 9 & 16 & 13 & $11.0 \mathrm{~h} \pm 10.3 \%$ & 13 \\
\hline
\end{tabular}

In general terms, this information allows the utility operator to observe how far from optimal the common behavior of consumers is. For example, consumers connected to nodes $2(n=2), 5(n=5), 6(n=6)$ and $13(n=13)$ should carry out their activities early in the morning in order to improve the whole HES performance. Moreover, a high variation for consumers connected to nodes 2 and 13 is observed because these consumers have a high degree of freedom to use their household appliances; this can be verified by observing the second and third columns for $n=2$ and $n=13$, respectively.

Regarding the benefits of DLC management, the proposed approach offers a moderate fuel savings between $7.24 \%$ and $27.1 \%$, depending on the month.

The analysis of a single day required 20.02 minutes, while the computational time analyzing a single month is between 166.92 minutes and 553.62 minutes.

\subsection{Management of DLC programs under uncertainty of wind generation}

Appling the methodology described in [40], the 25 scenarios $(Y=25)$ shown in grey lines were synthetically created using the profile with black line. Initially, 3,500 scenarios were randomly generated following the main profile (black line) with $90 \%$ autocorrelation, then reduced to only 25 scenarios by means of $k$-means++ clustering algorithm. Scenarios of high and low wind generation were simultaneously incorporated. 


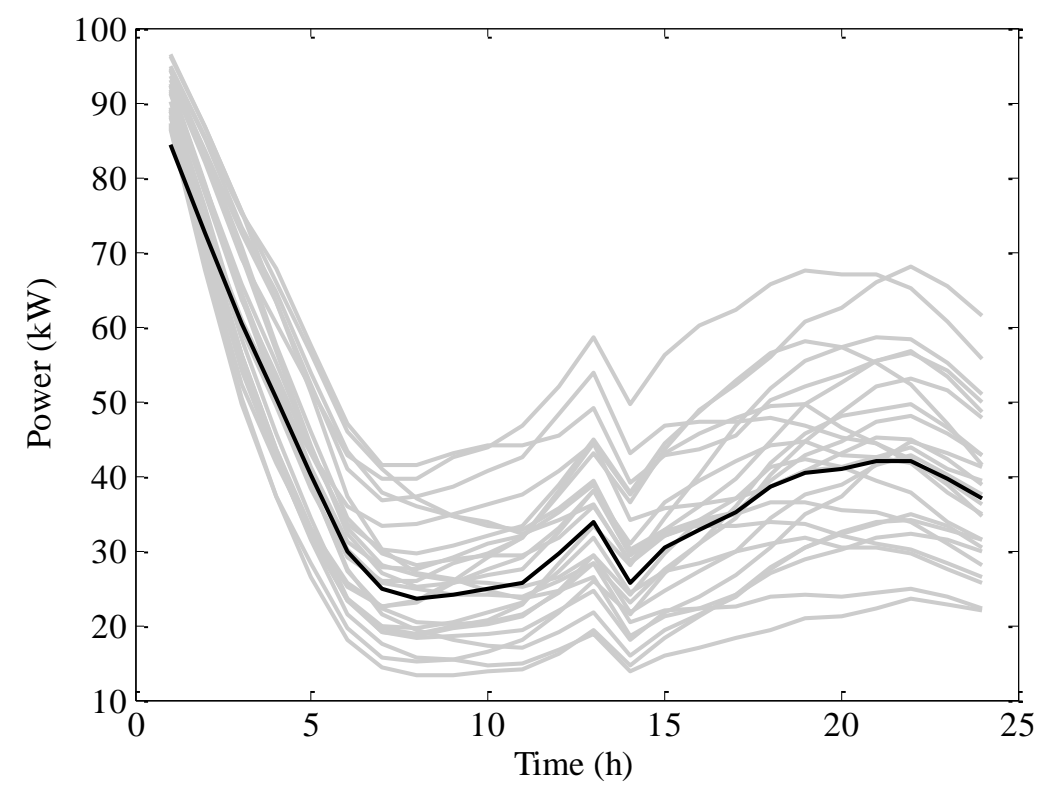

Fig. 20: Scenarios of wind power generation.

The proposed methodology can be applied to controllable loads with the characteristics shown in Fig. 2 (constant power consumption) and loads with any profile (variable power consumption).

To illustrate this condition, Table 5 shows power required by controllable loads $\left(\Delta P_{(n)}^{L}\right)$ represented by a profile instead of a single value. Note that for each node, the average power profile shown in Table 5 is equal to the values previously shown in Table 3.

Table 5: Controllable loads for case study.

\begin{tabular}{ccccc}
\hline$n$ & $C_{(n)}$ & & $\Delta P_{(n)}^{L}$ & \\
\hline 1 & 1 & 10.82 & 11.56 & ----- \\
2 & 8 & 12.81 & 11.97 & 10.90 \\
3 & 3 & 11.07 & ----- & ----- \\
4 & 2 & 10.38 & 10.84 & ---- \\
5 & 4 & 9.60 & 10.50 & ---- \\
6 & 7 & 11.05 & 11.90 & 12.01 \\
7 & 5 & 11.23 & ---- & --- \\
8 & 6 & 9.65 & 9.56 & 11.06 \\
9 & 9 & 11.35 & 10.66 & ----- \\
10 & 4 & 13.25 & 11.36 & ---- \\
11 & 1 & 12.71 & 11.31 & ----- \\
12 & 10 & 11.40 & 10.63 & ---- \\
13 & 8 & 12.30 & 10.61 & ----- \\
14 & 5 & 10.89 & ---- & ----- \\
15 & 2 & 11.37 & 11.58 & ---- \\
16 & 9 & 11.46 & 12.05 & 11.88 \\
17 & 6 & 11.26 & 10.00 & ----- \\
18 & 2 & 10.35 & 12.34 & ----- \\
19 & 3 & 12.60 & --- & \\
20 & 1 & 10.49 & 11.43 & - \\
\hline
\end{tabular}


Results previously discussed in subsection 4.1 allow us to identify a starting point for optimization analysis. Allocation of controllable loads at hours with abundant wind resources could be a reasonable approximation of the optimal solution. This reasoning can be used to estimate the profile of the consumer who fulfills these conditions in order to increase the efficiency of GA implementation. According to their corresponding contract and node, each controllable load can be used at the hour of maximum average wind power, taking into account the limits $t_{(j)}^{\min }$ and $t_{(j)}^{\max }$ established by the contract type. This procedure results in an individual $\left(\vec{a}_{(r)}\right)$, which is incorporated into the initial population of GA implementation. Appendix A1 presents the algorithm to create this starting point.

The proposed GA was implemented considering 10 individuals, 50 generations, a crossover rate of $95 \%$ and a $5 \%$ mutation rate. The computational complexity introduced by wind power scenarios has been compensated for by reducing the number of individuals and generations of GA. Fig. 21 shows the evolution of GA implementation, which required 19.5 minutes.

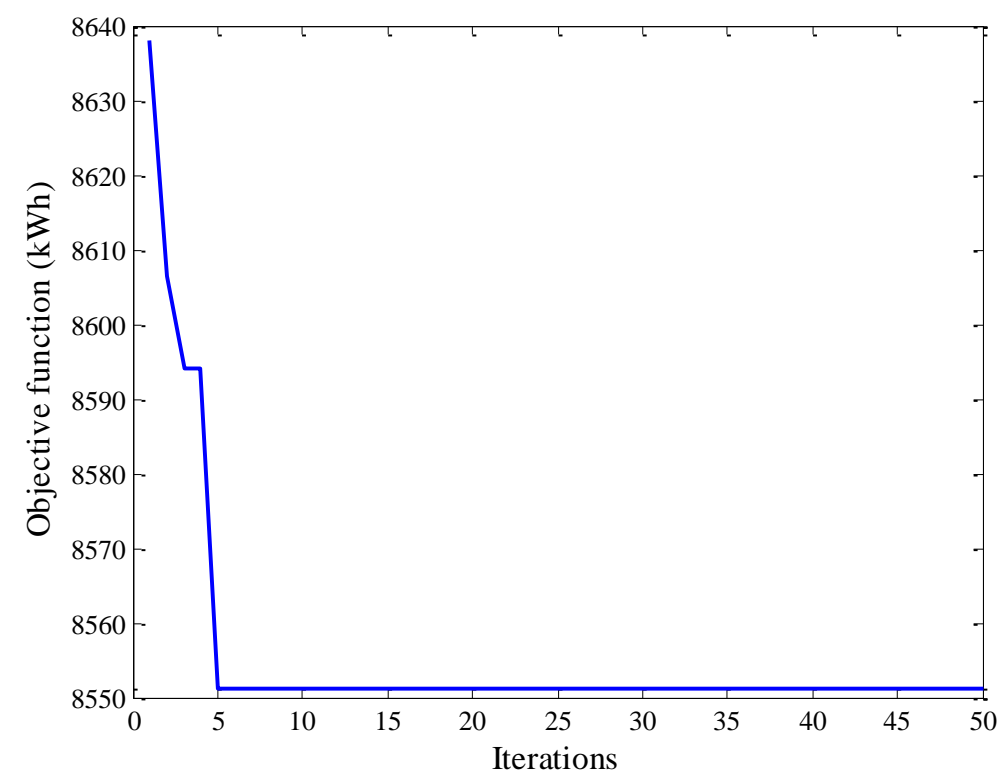

Fig. 21: GA evolution (Probabilistic optimization).

Table 6 presents the starting operation time of DLC devices per node of DS and the corresponding comparison with the base case.

Table 6: Allocation of DLC resources for probabilistic-daily analysis.

\begin{tabular}{ccccc}
\hline$n$ & $t_{(j)}^{\min } \forall j=C_{(n)}$ & $t_{(j)}^{\max } \forall j=C_{(n)}$ & $\begin{array}{c}t_{(j)} \forall C_{(n)} \\
(\text { Optimized } \\
\text { operation) }\end{array}$ & $\begin{array}{c}t_{(j)} \forall j=C_{(n)} \\
\text { (Base operation) }\end{array}$ \\
\hline 1 & 9 & 16 & 12 & 13 \\
2 & 1 & 24 & 1 & 13 \\
3 & 14 & 20 & 20 & 14 \\
4 & 16 & 20 & 19 & 16 \\
5 & 1 & 10 & 4 & 9 \\
6 & 7 & 11 & 7 & 9 \\
\hline
\end{tabular}




\begin{tabular}{ccccc}
\hline 7 & 12 & 24 & 14 & 12 \\
8 & 16 & 20 & 18 & 16 \\
9 & 7 & 11 & 10 & 10 \\
10 & 1 & 10 & 4 & 9 \\
11 & 9 & 16 & 12 & 13 \\
12 & 1 & 24 & 1 & 20 \\
13 & 1 & 24 & 1 & 13 \\
14 & 12 & 24 & 14 & 12 \\
15 & 16 & 20 & 19 & 16 \\
16 & 7 & 11 & 10 & 10 \\
17 & 16 & 20 & 18 & 16 \\
18 & 16 & 20 & 20 & 16 \\
19 & 14 & 20 & 12 & 14 \\
20 & 9 & 16 & & 13 \\
\hline
\end{tabular}

In addition, Fig. 22 shows the load profiles. Most controllable devices are operated in order to take advantage of the maximum available wind power. The expected fuel consumption is 856.26 liters, which represents a reduction (saving) of $16.59 \%$. The net load is expected between $37.56 \mathrm{~kW}$ and $250.9 \mathrm{~kW}$; the battery SOC is expected to be between 0.35 and 0.84 , while power production of the diesel generator is expected to be between $85.14 \mathrm{~kW}$ and $218.86 \mathrm{~kW}$.

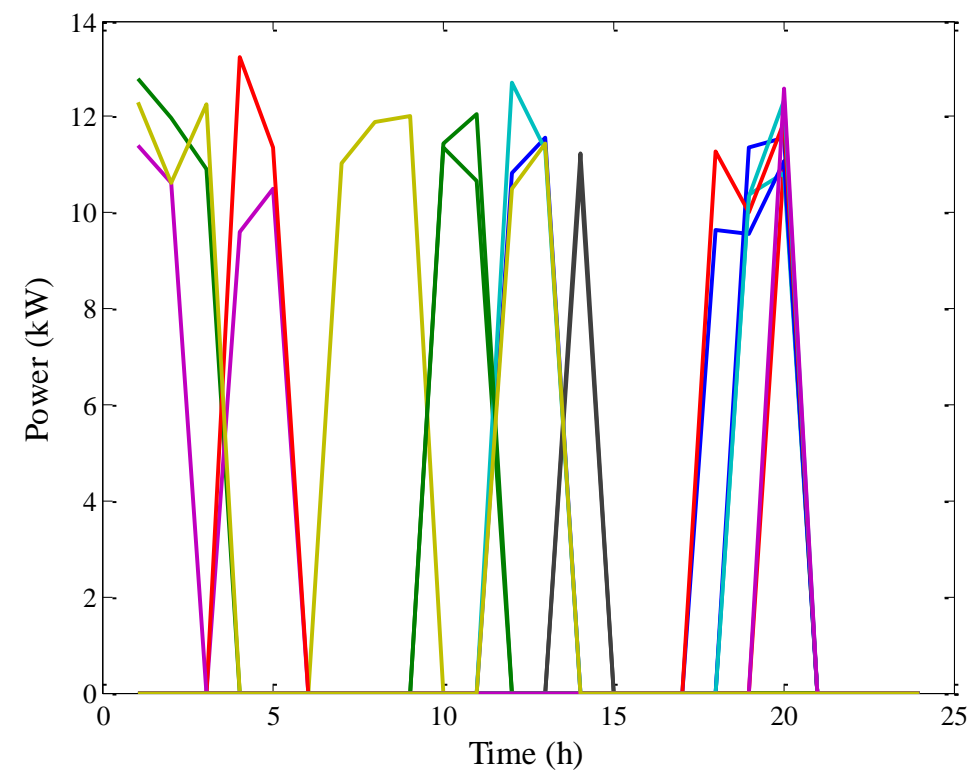

Fig. 22: Allocation of DLC resources (Probabilistic optimization).

\subsection{Implementation with other heuristic techniques}

The model based on GA was compared with an integer-coded gravitational search algorithm (GSA). The basic ideas of the original GSA [41] were adopted to implement an integer-coded version, due to the particular structure of the problem studied in this paper. In the integer-coded version used here, the magnitude of attraction forces between the heavier and lighter objects on the hypothetical mass system is represented using random integers. Specific details can be found in appendix A2. 
Using all of the information from the probabilistic case study in subsection 4.2, the management and control model presented in this paper was implemented using the integer-coded GSA.

During the GSA's implementation, high numbers of masses and iterations were selected to obtain a good solution to the problem, independent of the results from subsection 4.2 obtained by GA. In this regard, 150 masses and 200 iterations were used in the GSA's implementation.

Fig. 23 shows the evolution of the GSA, which required 1,169.846 minutes of simulation. The expected fuel consumption was 849.05 liters, which is lower than that obtained from the GA implementation in subsection 4.2 (856.26 liters). According to these results, the solution obtained from the GSA improves upon that obtained from GA by $0.849 \%$.

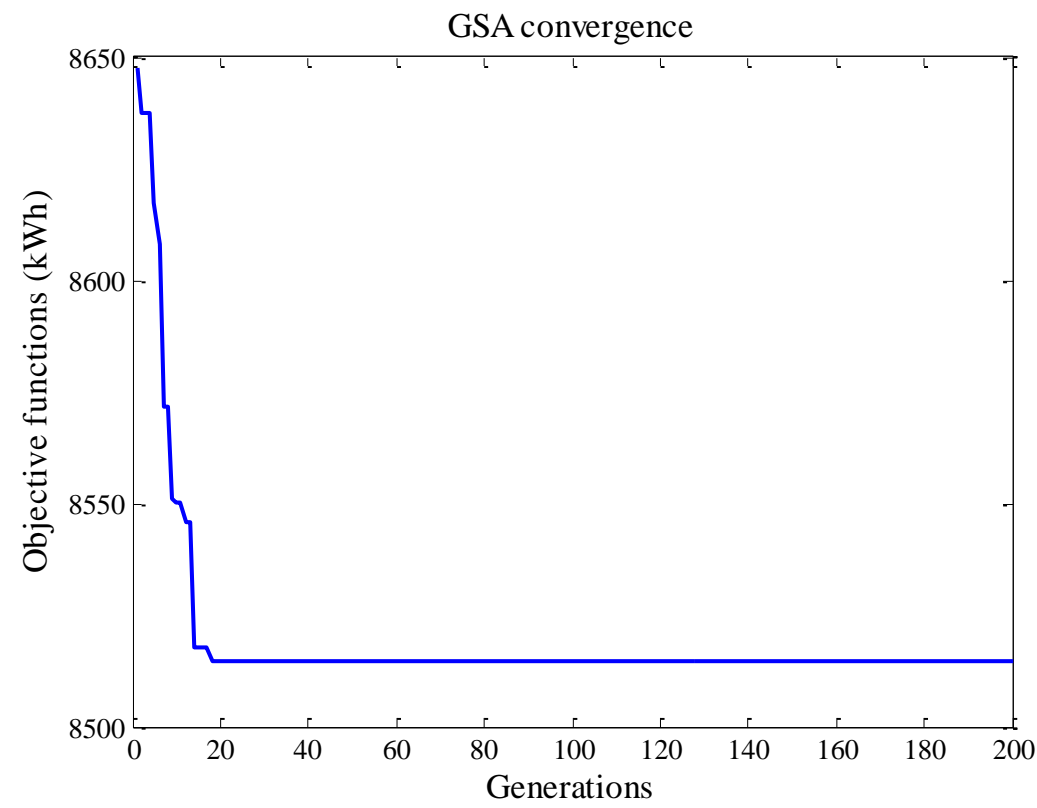

Fig. 23: GSA evolution (Probabilistic optimization).

Fig. 24 compares the GSA and GA with respect to DLC resource allocation. As can be observed, these two profiles have some similarities. 


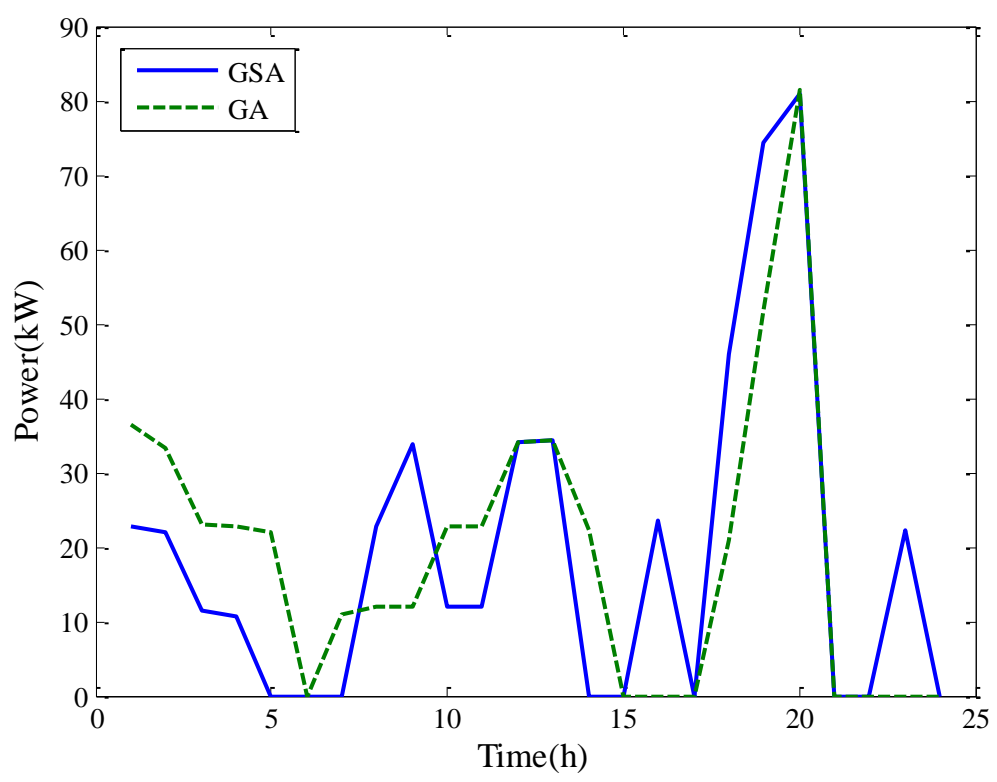

Fig. 24: DLC resources allocated by GSA (Probabilistic optimization).

\section{Conclusions and remarks}

In this paper, a DLC-contract scheme to be established between consumers enrolled in this DR program and the utility company was developed and illustrated. The proposed contract scheme offers flexibility to consumers in the way controllable loads can be used, as they can choose the time frame and power to be controlled by the utility company. This flexibility is expressed by means of the time interval defined in the DR contract $\left(\left[t_{(j)}^{\min }, t_{(j)}^{\max }\right]\right)$, as well as the value of the power to be controlled by the utility operator $\left(\Delta P_{(n)}^{L}\right)$. This reasoning aims to incentivize consumers to enroll in a DLC program.

The proposed scheme shows the advantages of adopting DLC programs from an energy-efficiency perspective, since available renewable generation is consumed and stored to be later used by loads devoted to critical tasks (critical loads).

On one hand, the implementation of a management algorithm as an energy block (subsection 4.1) and a load profile (subsection 4.2) illustrates the capabilities of the proposed approach to represent realistic conditions. On the other hand, in implementing the proposed technique in the modern SG, each consumer $(n)$ connected to the DS could be understood as a load aggregator instead of a single consumer. In a general sense, the functionalities of the methodology developed in this work could be extended to other type of ESs.

The computational burden could be intensive, as a monthly or seasonal analysis is required during DLC-contract designing. Incorporation of parallel computing techniques can be used to reduce the computational time.

\section{Acknowledgment}

The authors would like to thank the anonymous reviewers for their assertive comments and suggestions.

\section{Appendix}


Appendix A1. GA initialization

This subsection describes how GA initialization can be carried out using wind power scenarios. The first step consists of calculating the average wind power profile $\left(P_{(h)}^{W, a v g}\right)$ according to $(\mathrm{A} 1)$,

$$
P_{(h)}^{W, a v g}=\sum_{y=1}^{Y} \frac{1}{Y} P_{(h, y)}^{W} \forall h=1, \ldots, H .
$$

Depending of the contract type $(j)$, the hour at which wind production reaches its maximum power $\left(h_{(j)}^{W, \max }\right)$ within the time interval $\left(t_{(j)}^{\min }, t_{(j)}^{\max }\right)$ is calculated. This idea is expressed in $\mathrm{A} 2$,

$$
h_{(j)}^{W, \max }=h \mid \max \left\{P_{\left(t_{(j)}^{\min }\right)}^{W, \ldots, P_{\left(t_{(j)}^{\max }-\Delta t_{(j)}+1\right)}^{W, a v g}}\right\} \forall j=1, \ldots, J .
$$

Using these results $\left(h_{(j)}^{W, \max } \forall j=1, \ldots, J\right)$, the algorithm of Fig. A1 is applied for contract type $j=1, \ldots, J$. From this procedure, the value of the row $\left(m_{(j)}^{o}\right)$ required for the initialization is obtained.

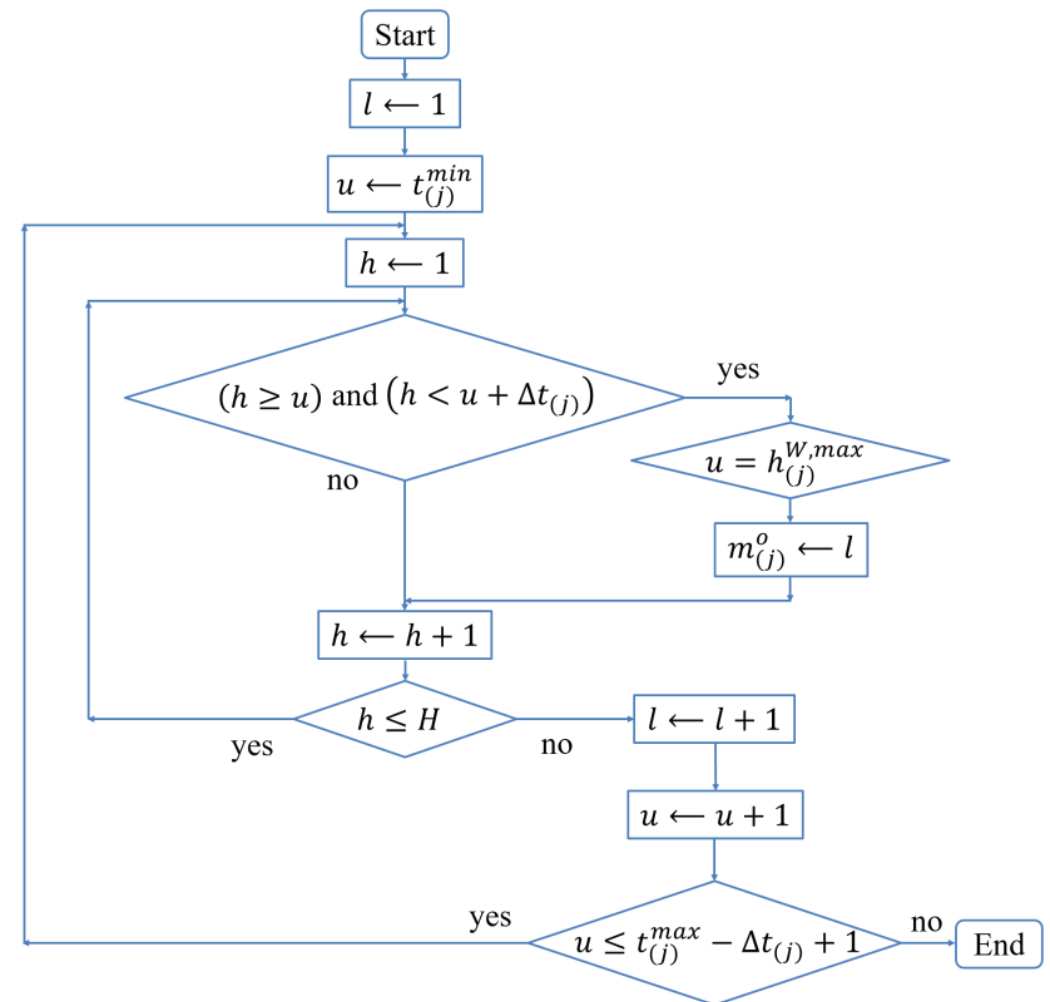

Fig. A1: Algorithm to initialize GA.

The initialization vector $\left(\vec{a}_{(R)}^{o}\right)$ is created according to (A3) and (A4),

$$
a_{(R, j)}^{o}=m_{(j)}^{o} \forall j=1, \ldots, J
$$




$$
\vec{a}_{(R)}^{o}=\left[\begin{array}{lllll}
a_{(R, 1)}^{o} & \cdots & a_{(R, j)}^{o} & \cdots & a_{(R, J)}^{o}
\end{array}\right] .
$$

Finally, the vector $\vec{a}_{(R)}^{o}$ is added to the last position of the initial population (A5), which is used during the analysis of the first generation.

$$
A=\left[\begin{array}{c}
\vec{a}_{(1)} \\
\vdots \\
\vec{a}_{(r)} \\
\vdots \\
\vec{a}_{(R)}^{=} \vec{a}_{(R)}^{o}
\end{array}\right]
$$

Appendix A2. Integer-coded GSA

The GSA [42] was initially proposed to solve problems with continuous variables. However, the problem analyzed in this paper requires an optimization technique that can work with integers since it chooses the optimal row from a controllable load matrix, according to the DR contract in which the consumer is enrolled.

During a determined iteration of the GSA, the mass for each possible solution $\left(f_{A(r)} \forall r=1, \ldots, R\right)$ is calculated using A6.

$$
f_{A(r)}=\frac{(R+1)-r}{\sum_{l=1}^{R}\{(R+1)-l\}} \forall r=1, \ldots, R
$$

Then, the minimum $\left(f_{A}^{\min }\right)$ and maximum $\left(f_{A}^{\max }\right)$ fitness as well as the object with the highest mass $\left(\vec{a}_{(r)}^{\text {opt }}\right)$ are identified according to A7, A8, and A9.

$$
\begin{gathered}
f_{A}^{\min }=\min \left\{f_{A(r)} \forall r=1, \ldots, R\right\} ; \\
f_{A}^{\text {max }}=\max \left\{f_{A(r)} \forall r=1, \ldots, R\right\} ; \\
\vec{a}_{(r)}^{\text {opt }}=\vec{a}_{(r)} \mid f_{A(r)}=f_{A}^{\text {max }} .
\end{gathered}
$$

In this work, the movement of light masses toward heavy ones was represented using random integers. To carry out this task, the function $\left(g_{A(r)} \forall r=1, \ldots, R\right)$ is introduced as $\mathrm{A} 10$, in which the function $\operatorname{INT}(\cdot)$ truncates the floating point number on its argument.

$$
g_{A(r)}=I N T\left(\left[1-\frac{f_{A(r)}-f_{A}^{\text {min }}}{f_{A}^{\text {max }}-f_{A}^{\text {min }}}\right] J\right) \forall r=1, \ldots, R .
$$

This function defines how the position of the possible solution under evaluation (object) will be modified to put this object on the optimal path.

Each object $\left(\vec{a}_{(r)} \forall r=1, \ldots, R\right)$ is represented by a vector according to Fig. 7, where each element $\left(a_{(r, j)}\right)$ represents the position of the object $(r)$ on each dimension $(j=1, \ldots, J)$. The function $\left(g_{A(r)} \forall r=1, \ldots, R\right)$ results in an integer between 1 and $J$ according to the mass $\left(f_{A(r)}\right)$ of the solution under evaluation. It represents the number 
of dimensions $(j)$ in which the position of individual $r$ will be modified. Note that $g_{A(r)}$ increases when the object has a mass close to the minimum one, which means that the object's position is far from the optimal one, and it will be moved in many dimensions $(j)$ on the optimal path.

Conversely, when an object with a high mass is evaluated with A10, this function results in a value close to 0 . This means that objects with a high mass (fitness) are located close to the optimal position, so their coordinates do not need to be changed.

Once $g_{A(r)}$ has been calculated for all masses and the object on the optimal position $\left(\vec{a}_{(r)}^{o p t}\right)$ has been identified, the algorithm shown in Fig. A2 is applied, where the function $R N D\left(\varepsilon_{\min }, \varepsilon_{\max }\right)$ results in an integer between the integers $\varepsilon_{\min }$ and $\varepsilon_{\max }$.

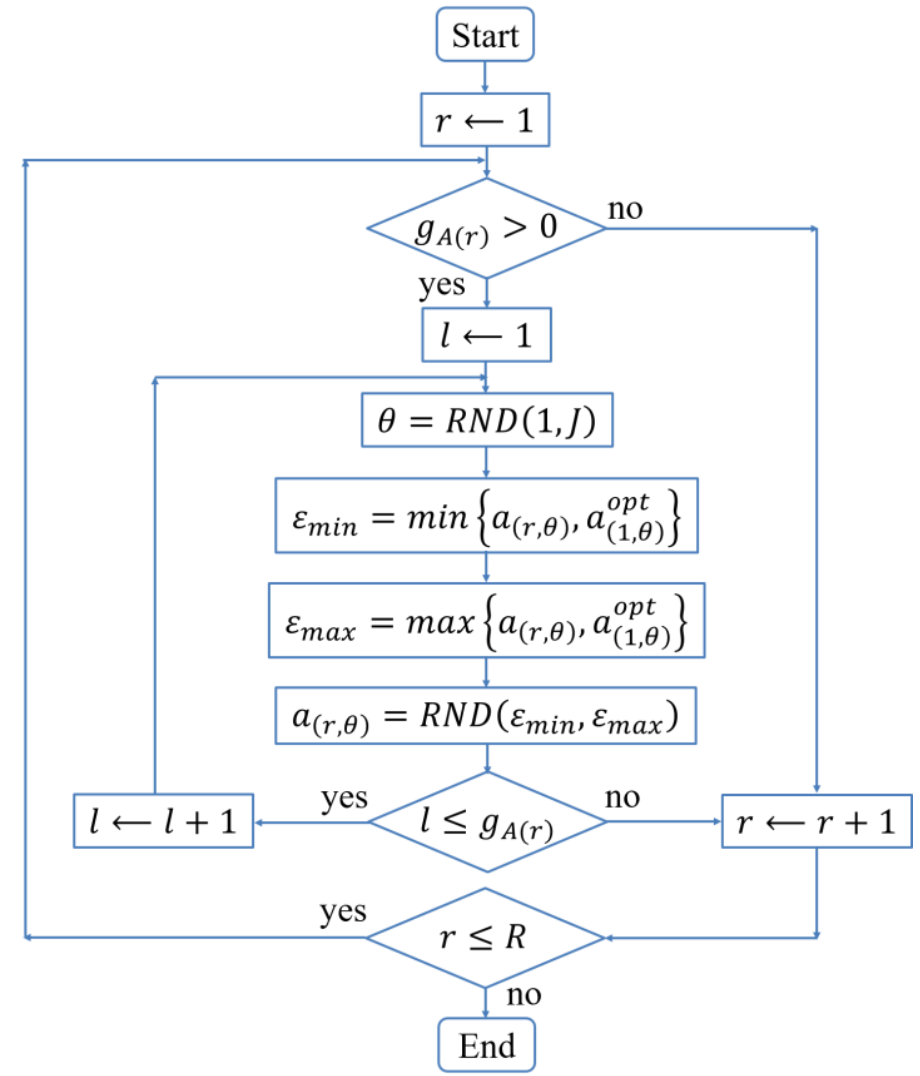

Fig. A2: Algorithm to implement the integer-coded GSA.

According to Fig. A2, select a determined object $(r)$. If the function $g_{A(r)}$ is higher than 0 (if this object is not in the optimal position), then the object will be randomly moved in $g_{A(r)}$ dimensions. A dimension to be modified $(\theta)$ is chosen using a random integer generator between 1 and $J(R N D(1, J)$ in Fig. A2).

The movement will be between the actual position $\left(a_{(r, \theta)}\right)$ of the object $(r)$ under evaluation and the actual position of the heaviest object $\left(a_{(1, \theta)}^{o p t}\right)$. The variables $\varepsilon_{\min }$ and $\varepsilon_{\max }$ are calculated to identify the points on the optimal path. Then, the object's position for the next iteration, on the dimension $\theta$, is calculated using a random-integer-generation subroutine $\left(a_{(r, \theta)}=R N D\left(\varepsilon_{\min }, \varepsilon_{\max }\right)\right.$ in Fig. A2).

\section{References}


[1] Nolan S, O'Malley M. Challenges and barriers to demand response deployment and evaluation. Appl Energy 2015;152:1-10.

[2] Guo P, Li VOK, Lam JCK. Smart demand response in China: challenges and drivers. Energ Policy 2017;107:1-10.

[3] Jordehi AR. Optimisation of demand response in electric power systems, a review. Renew Sust Energ Rev 2019;103:308-319.

[4] Liu T, Zhang D, Wang S, Wu T. Standardized modelling and economic optimization of multi-carrier energy systems considering energy storage and demand response. Energy Convers Manage 2019;182:126-142.

[5] Hosseinnia H, Tousi B. Optimal operation of DG-based micro grid (MG) by considering demand response program (DRP). Electr Power Syst Res 2019;167:252260.

[6] Ihsan A, Jeppesen M, Brear MJ. Impact of demand response on the optimal, technoeconomic performance of a hybrid, renewable energy power plant. Appl Energy 2019;238:972-984.

[7] Wang J, Shi Y, Zhou Y. Intelligent demand response for industrial energy management considering thermostatically controlled loads and EVs. IEEE Trans Ind Informat 2019; In Press.

[8] Alipour M, Zare K, Seyedi H, Jalali M. Real-time price-based demand response model for combined heat and power systems. Energy 2019;168:1119-1127.

[9] Lu Q, Yu H, Zhao K, Leng Y, Hou J, Xie P. Residential demand response considering distributed PV consumption: a model base on China's PV policy. Energy 2019; 172:443-456.

[10] Lu R, Hong SH. Incentive-based demand response for smart grid with reinforcement learning and deep neural network. Appl Energy 2019;236:937-949.

[11] Mocanu E, Mocanu DC, Nguyen PH, Liotta A, Webber ME, Gibescu M, Slootweg JG. On-line building energy optimization using deep reinforcement learning. IEEE Trans Smart Grid 2019; In Press.

[12] Lu T, Wang Z, Wang J, Ai Q, Wang C. A data-driven Stackelberg market strategy for demand response-enabled distribution systems. IEEE Trans Smart Grid 2019; In Press.

[13] Liu N, Wang J, Wang L. Hybrid energy sharing for multiple microgrids in an integrated heat-electricity energy system. IEEE Trans Sustain Energy 2019; In Press.

[14] Kazmi S, Javaid N, Mughal MJ, Akbar M, Ahmed SH, Alrajeh N. Towards optimization of metaheuristic algorithms for IoT enabled smart homes targeting balanced demand and supply of energy. IEEE Access 2019; In Press. 
[15] Golmohamadi H, Keypour R, Bak-Jensen B, Pillai JR. A multi-agent based optimization of residential and industrial demand response aggregators. Int $\mathrm{J}$ Electr Power Energy Syst 2019;107:472-485.

[16] Wu J, Zhang B, Jiang Y, Bie P, Li H. Chance-constrained stochastic congestion management of power systems considering uncertainty of wind power and demand side response. Int J Electr Power Energy Syst 2019;107:703-714.

[17] Hajibandeh N, Ehsan M, Soleymani S, Shafie-khah M, Catalão JPS. Prioritizing the effectiveness of a comprehensive set of demand response programs on wind power integration. Int J Electr Power Energy Syst 2019;107:149-158.

[18] Davatgaran V, Saniei M, Mortazavi SS. Smart distribution system management considering electrical and thermal demand response of energy hubs. Energy 2019;169:38-49.

[19] Yu D, Liu H, Bresser C. Peak load management based on hybrid power generation and demand response. Energy 2018;163:969-985.

[20] Fell MJ, Shipworth D, Huebner GM, Elwell CA. Public acceptability of domestic demand-side response in Great Britain: The role of automation and direct load control. Energy Research \& Social Science 2015;9:72-84.

[21] Xu X, Chen C-f, Zhu X, Hu Q. Promoting acceptance of direct load control programs in the United States: Financial incentive versus control option. Energy 2018;147:1278-1287.

[22] Stenner K, Frederiks ER, Hobman EV, Cook S. Willingness to participate in direct load control: the role of consumer distrust. Appl Energy 2017;189:76-88.

[23] Giorsetto P, Utsurogi KF. Development of a new procedure for reliability modeling of wind turbine generators. IEEE Trans Power Appar Syst 1983;PAS-102(1):134-143.

[24] Qiu X, Nguyen TA, Guggenberger JD, Crow ML, Elmore AC. A field validated model of a vanadium redox flow battery for microgrids. IEEE Trans Smart Grid 2014;5(4):1592-1601.

[25] Nguyen TA, Qiu X, Guggenberger JD, Crow ML, Elmore AC. Performance characterization for photovoltaic-vanadium redox battery microgrid systems. IEEE Trans Sustain Energy 2014;5(4):1379-1388.

[26] Nguyen TA, Crow ML, Elmore AC. Optimal sizing of a vanadium redox battery system for microgrid systems. IEEE Trans Sustain Energy 2015;6(3):729-737.

[27] Rampinelli GA, Krenzinger A, Romero FC. Mathematical models for efficiency of inverters used in grid connected photovoltaic systems. Renew Sust Energ Rev 2014;34:578-587.

[28] Short TA. Electric power distribution handbook. Boca Raton, Florida: CRC Press LLC; 2004. 
[29] Teng J-H. A direct approach for distribution system load flow solutions. IEEE Trans Power Del 2003;18(3):882-887.

[30] Deb AK. Theory of Transmission Line Ampacity. In: Power line ampacity system: theory, modeling, and applications. Boca Raton, Florida: CRC Press LLC; 2000, p. $27-$ 59.

[31] Lujano-Rojas JM, Monteiro C, Dufo-López R, Bernal-Agustín JL. Optimum residential load management strategy for real time pricing (RTP) demand response programs. Energ Policy 2012;45:671-679.

[32] Lujano-Rojas JM, Monteiro C, Dufo-López R, Bernal-Agustín JL. Optimum load management strategy for wind/diesel/battery hybrid power systems. Renew Energ 2012;44:288-295.

[33] Kovács A. On the computational complexity of tariff optimization for demand response management. IEEE Trans Power Syst 2018;33(3):3204-3206.

[34] Barley CD, Winn CB. Optimal dispatch strategy in remote hybrid power systems. Sol Energy 1996;58(4-6):165-179.

[35] Dufo-López R, Bernal-Agustín JL. Design and control strategies of PV-diesel systems using genetic algorithms. Sol Energy 2005;79:33-46.

[36] Pfenninger S, Staffell I. Renewables.ninja. https://www.renewables.ninja/; 2019 [accessed 02.15.2019].

[37] Pfenninger S, Staffell I. Long-term patterns of European PV output using 30 years of validated hourly reanalysis and satellite data. Energy 2016;114:1251-1265.

[38] Staffell I, Pfenninger S. Using bias-corrected reanalysis to simulate current and future wind power output. Energy 2016;114:1224-1239.

[39] Instituto para la Diversificación y Ahorro de la Energía (IDAE). Consumos del sector residencial en España resume de información básica. Ministerio de Industria, Energía y http://www.idae.es/uploads/documentos/documentos_Documentacion_Basica_Residenc ial_Unido_c93da537.pdf; 2019 [accessed 02.15.2019].

[40] Osório GJ, Lujano-Rojas JM, Matias JCO, Catalão JPS. A fast method for the unit scheduling problem with significant renewable power generation. Energy Convers Manage 2015;94:178-189.

[41] Rashedi E, Nezamabadi-pour H, Saryazdi S. GSA: A gravitational search algorithm. Information Sciences 2009;179:2232-2248. 